OPEN ACCESS

Edited by:

Jianmei Wu Leavenworth, University of Alabama at Birmingham,

United States

Reviewed by:

Adriana Mantegazza,

Thomas Jefferson University,

United States

Tomoko Hayashi,

University of California, San Diego,

United States

${ }^{*}$ Correspondence:

Joke M. M. den Haan

j.denhaan@amsterdamumc.nl

Specialty section:

This article was submitted to

Cancer Immunity

and Immunotherapy,

a section of the journal

Frontiers in Immunology

Received: 23 December 2021 Accepted: 01 February 2022

Published: 18 February 2022

Citation:

Nijen Twilhaar MK, Czentner L, Bouma RG, Olesek K, Grabowska J, Wang AZ, Affandi AJ, Belt SC, Kalay H,

van Nostrum CF, van Kooyk $Y$, Storm $G$ and den Haan JMM (2022) Incorporation of Toll-Like Receptor Ligands and Inflammasome Stimuli in GM3 Liposomes to Induce Dendritic Cell Maturation and T Cell Responses.

Front. Immunol. 13:842241. doi: 10.3389/fimmu.2022.842241

\section{Incorporation of Toll-Like Receptor Ligands and Inflammasome Stimuli in GM3 Liposomes to Induce Dendritic Cell Maturation and T Cell Responses}

\author{
Maarten K. Nijen Twilhaar ${ }^{1}$, Lucas Czentner ${ }^{2}$, Rianne G. Bouma ${ }^{1}$, Katarzyna Olesek ${ }^{1}$, \\ Joanna Grabowska ${ }^{1}$, Aru Zeling Wang ${ }^{1}$, Alsya J. Affandi ${ }^{1}$, Saskia C. Belt ${ }^{1}$, Hakan Kalay ${ }^{1}$, \\ Cornelus F. van Nostrum ${ }^{2}$, Yvette van Kooyk ${ }^{1}$, Gert Storm ${ }^{2,3,4}$ and Joke M. M. den Haan ${ }^{1 *}$ \\ 1 Department of Molecular Cell Biology and Immunology, Cancer Center Amsterdam, Amsterdam Infection and Immunity \\ Institute, Amsterdam University Medical Center, Vrije Universiteit Amsterdam, Amsterdam, Netherlands, ${ }^{2}$ Department of \\ Pharmaceutics, Faculty of Science, Utrecht University, Utrecht, Netherlands, ${ }^{3}$ Department of Biomaterials Science and \\ Technology, Faculty of Science and Technology, University of Twente, Enschede, Netherlands, ${ }^{4}$ Department of Surgery, \\ Yong Loo Lin School of Medicine, National University of Singapore, Singapore, Singapore
}

Cancer vaccination aims to activate immunity towards cancer cells and can be achieved by delivery of cancer antigens together with immune stimulatory adjuvants to antigen presenting cells (APC). APC maturation and antigen processing is a subsequent prerequisite for T cell priming and anti-tumor immunity. In order to specifically target APC, nanoparticles, such as liposomes, can be used for the delivery of antigen and adjuvant. We have previously shown that liposomal inclusion of the ganglioside GM3, an endogenous ligand for CD169, led to robust uptake by CD169-expressing APC and resulted in strong immune responses when supplemented with a soluble adjuvant. To minimize the adverse effects related to a soluble adjuvant, immune stimulatory molecules can be incorporated in liposomes to achieve targeted delivery of both antigen and adjuvant. In this study, we incorporated TLR4 (MPLA) or TLR7/8 (3M-052) ligands in combination with inflammasome stimuli, 1-palmitoyl-2-glutaryl-sn-glycero-3-phosphocholine (PGPC) or muramyl dipeptide (MDP), into GM3 liposomes. Incorporation of TLR and inflammasome ligands did not interfere with the uptake of GM3 liposomes by CD169-expressing cells. GM3 liposomes containing a TLR ligand efficiently matured human and mouse dendritic cells in vitro and in vivo, while inclusion of PGPC or MDP had minor effects on maturation. Immunization with MPLA-containing GM3 liposomes containing an immunogenic synthetic long peptide stimulated $\mathrm{CD}^{+}$and $\mathrm{CD} 8^{+} \mathrm{T}$ cell responses, but additional incorporation of either PGPC or MDP did not translate into stronger immune responses. In conclusion, our study indicates that TLRL-containing GM3 liposomes are effective vectors to induce DC maturation and T cell priming and thus provide guidance for further selection of liposomal components to optimally stimulate anti-cancer immune responses.

Keywords: liposomes, toll-like receptor ligand, inflammasome stimuli, dendritic cells, $\mathrm{T}$ cells, vaccination, cancer 


\section{INTRODUCTION}

Tumor cells are derived from healthy cells and contain multiple somatic mutations due to, for example, errors in DNA replication, failure in DNA repair and exposure to carcinogens (1). As mutations accumulate and the malignant transformation of tumor cells gradually develops, there is a progressive loss in classification of these cells as 'self'. Indeed, malignant transformation coincides with the expression of tumor antigens, that can either be aberrantly expressed proteins, overexpressed proteins or newly developed tumor-specific antigens (2). Subsequently, the immune system can respond to these 'non-self malignantly transformed cells, leading to tumor cell killing, especially by $\mathrm{CD} 8^{+} \mathrm{T}$ cells (3). The efficacy of immunotherapies such as immune checkpoint inhibition (ICI) illustrates the power of the immune system in (re-)enforcing the anti-tumor response (4). However, clinical responses are not observed in all patients and can be linked to pre-existing immune responses (5). Since cancer vaccination aims to induce antigenspecific $\mathrm{T}$ cell responses in patients, it is expected that combining ICI with vaccination will synergistically enforce the immune system and thereby will improve clinical outcome (6-8).

A prerequisite for a successful cancer vaccine lays in the activation of dendritic cells (DC) to prime T cells. DC can be activated by pathogen-associated molecular patterns, such as Toll-like receptor (TLR) agonists, which results in cellular maturation and coincides with upregulation of costimulatory molecules and cytokine secretion (9). Indeed, DC maturation is pivotal for effective cancer vaccination, as $\mathrm{T}$ cell priming in the absence of co-stimulation results in tolerance induction (9). Coinciding with DC maturation, vaccine antigen can be processed and subsequently cross-presented in MHC class I or in MHC class II to activate $\mathrm{CD}^{+}$or $\mathrm{CD}^{+}{ }^{+}$cells, respectively (10). Interestingly, stimulation of DC with TLR agonists increases the capacity of DC to cross-present co-delivered antigen to $\mathrm{CD}^{+} \mathrm{T}$ cells $(11,12)$. Therefore, co-delivery of antigen and adjuvant by means of a carrier is an interesting approach to maximize immune responses to the vaccine antigen. TLR can reside embedded within the plasma membrane or in endosomal compartments, which correlates with the nature of their ligands (13). In addition to TLR, also various innate cytosolic receptors such as retinoic acid-inducible gene I (RIGI), melanoma differentiation-associated protein 5 (MDA5) and nucleotide-binding oligomerization domain-containing protein 2 (NOD2) can induce cellular maturation upon recognition of (viral) RNA (RIG-I and MDA5) or bacterial peptidoglycans (NOD2) (14). Various types of nanoparticles can be used as vaccine vector. Among others, liposomes received attention because of their versatile nature which allows them to transfer both hydrophilic as well as hydrophobic cargo (15). Furthermore, liposomes can be surface-decorated with targeting moieties, to facilitate cellular targeting $(16,17)$. Thus, by use of liposomes and combining both antigen and adjuvant in a single particle that is targeted to a cell of interest in vivo, the potency of cancer vaccination is expected to be augmented $(18-20)$.
DCs are the only cells that can stimulate naïve $T$ cell responses, but also consist of different subsets that differ in their capacity to (cross-)present antigen (21-23). DC can be broadly divided into conventional DC1 ( $\mathrm{cDC} 1), \mathrm{cDC} 2$ and plasmacytoid DC (pDC) (24). Of these subsets, the transcription factor Batf3-dependent $\mathrm{CDC} 1$ is especially pivotal in the anti-cancer responses (25). Indeed, high numbers of $\mathrm{CDC1}$ in the tumor microenvironment is associated with favorable prognosis (26). Within the tumor microenvironment, cDC1 secrete various chemokines that are important for $\mathrm{T}$ cell attraction and survival $(26,27)$. Importantly, $\mathrm{cDC} 1$ have a superior capacity to recognize dying cells and to cross-present antigen and thereby activate $\mathrm{CD} 8^{+} \mathrm{T}$ cells, as compared to other DC subtypes $(21-23,28,29)$. In addition, it is becoming increasingly clear that $\mathrm{CDC} 1$ can also play a pivotal role in the initiation of $\mathrm{CD}^{+} \mathrm{T}$ cell responses $(30,31)$. Because of these traits, $\mathrm{CDC} 1$ are considered to be an attractive target for various cancer vaccination strategies $(23,32-34)$.

A recently described alternative cellular target for cancer vaccines are CD169-expressing macrophages (18). These cells are strategically located in the spleen to capture particulate antigen and marked by their high expression of CD169, also known as Siglec-1 or sialoadhesin (35-38). This adhesion molecule is involved in sequestering pathogens such as human immunodeficiency virus (HIV) as well as SARS-CoV-2 (39-42). Importantly, upon capture of particulate antigen, CD169expressing macrophages were found to efficiently transfer vaccine antigen to $\mathrm{cDC1}$ to elicit an immune response, as observed for antibody-mediated targeting of antigen to CD169expressing macrophages $(43,44)$. The natural ligand of CD169 are $\alpha 2,3$-linked sialic acids that are present in gangliosides incorporated in viruses and these gangliosides also facilitate targeting of artificial viral nanoparticles to these cells (45-47). We have recently shown that inclusion of the ganglioside GM3 in antigen-containing liposomes resulted in robust targeting to CD169-expressing macrophages and, when co-injected with a strong soluble adjuvant (activating anti-CD40 antibody and poly IC), induced $\mathrm{CD}^{+} \mathrm{T}$ cell responses that were dependent on cDC1 $(48,49)$. In addition to the endogenous ligands for the receptor, CD169-expressing macrophages could also be targeted with liposomes that harbored a synthetic ligand for CD169 (50, 51). Hence, targeting vaccine components to CD169-expressing macrophages is an attractive strategy to induce $\mathrm{CDC1}$ activation and subsequent adaptive immune responses.

Various strategies are employed in the design of nanovaccines to activate the immune system and TLR agonists are ubiquitously used to induce cellular maturation $(19,20)$. Recently, it was also noted that low level inflammation, caused by cellular exposure to oxidized lipids in combination with a TLR agonist, induces robust $\mathrm{T}$ cell responses through the induction of a hyperactive state of DC (52). However, the precise role of oxidized lipids in cellular maturation and cytokine secretion is not necessarily beneficial, as a link between exposure to oxidized lipids and diminished immune responses was also observed (53). Thus, the effect of oxidized lipid may be dependent on tissue context and time, while the nature of the recipient cell type also appears to 
play a role (54). In addition to oxidized lipids, beneficial synergistic effects on cellular maturation were observed when muramyl dipeptide (MDP), a ligand for NOD2, was combined with a ligand of TLR4 or $7 / 8(55,56)$. Mechanistically, both oxidized lipids and MDP can directly or indirectly, induce activation of the inflammasome, without causing cellular death by pyroptosis $(52,55,56)$. Thus, combining TLR ligands with inflammasome stimuli may be an attractive approach to harness anti-cancer immunity, without the need to supplement antigencontaining liposomes with a strong soluble adjuvant. In this work, we prepared liposomes that contain the targeting moiety GM3 and a TLR ligand plus an inflammasome ligand or a combination of one TLR ligand and one inflammasome ligand. We assessed to what extent dual liposomal delivery of TLR ligands and/or inflammasome ligands to CD169-expressing cells aid cellular maturation of human and mouse DCs in vitro and in vivo. Moreover, we assessed how these adjuvants affect the magnitude of the $\mathrm{T}$ cell response as compared to the strong soluble adjuvant (activating anti-CD40 antibody and poly IC) we used earlier $(48,49)$. These data indicate that GM3/TLR ligandcontaining liposomes are suitable vectors for cancer vaccines, but that combined stimulation of TLR and inflammasome components via CD169-targeted GM3-containing liposomal delivery yields minor additive effects on the magnitude of the $\mathrm{T}$ cell response.

\section{MATERIALS AND METHODS}

\section{Liposome Preparation and Characterization}

Liposomes were prepared from a mixture of phosphatidylcholine, phosphatidylglycerol (Lipoid GmbH, Ludwigshafen, Germany) and cholesterol (Sigma Aldrich, Darmstadt, Germany) in a 3.8:1:2.5 molar ratio, dissolved in methanol/chloroform (2:1). Subsequently, $15 \mu \mathrm{mol}$ of the lipid mixture was transferred to a round bottom flask. Where indicated, supplemented with GM3 (3 mol\%) (Merck, Darmstadt, Germany), telratolimod/3M-052 (2 mol\%) (Bio-connect, Huissen, the Netherlands), monophosphoryl lipid A (MPLA) (2 mol\%) (Merck, Darmstadt, Germany), 1-palmitoyl-2-glutaryl-sn-glycero-3phosphocholine (PGPC) (2 mol\%) (Merck, Darmstadt, Germany) and/or L18-MDP (2 mol\%) (In vivo Gen, Toulouse, France). Additionally, $0.1 \mathrm{~mol} \%$ of the lipophilic fluorescent tracer DiD ( $1^{\prime}$-dioctadecyl-3,3,3',3'-tetramethyl indodicarbocyanine, Life Technologies, Frederick, MD, USA) was incorporated. Next, the organic phase was evaporated under reduced pressure using a rotavapor and lipid films were hydrated in $10 \mathrm{mM}$ HEPES buffer $\mathrm{pH}$ 7.4. Where indicated, this buffer contained $1 \mathrm{mg} / \mathrm{ml}$ of immunogenic $\mathrm{OVA}_{247-279}$-peptide (produced in house). Liposomes were sized through stacked polycarbonate filters, $400 / 200 \mathrm{~nm}$, using high pressure nitrogen and sequentially concentrated and washed from nonencapsulated peptide by ultracentrifugation $(200,000 \mathrm{~g}$, Beckman Coulter). The liposome pellet was resuspended in HEPES buffer as described above. The phosphate content, liposomal mean size, polydispersity index (PDI), and zetapotential were determined as previously described (49).

\section{CD169 Fc ELISA}

Liposomes were diluted in ethanol to a final concentration of 25 $\mu \mathrm{M}$ phospholipids and coated on Immuno MaxiSorp plates (NUNC, Roskilde, Denmark). 1\% BSA (BSA; Fraction V, Fatty acid free, Calbiochem, San Diego, CA, USA) diluted in PBS was used to block coated plates. Next, samples were incubated with CD169 Fc or its mutant form (CD169 Fc R97A) $(2 \mu \mathrm{g} / \mathrm{mL})$ for 1 hour at room temperature (kindly provided by Prof. Dr. P.R. Crocker, University of Dundee) (57). Then, peroxidaseconjugated goat anti-human IgG (Jackson ImmunoResearch, Ely, UK) was added for an additional 30 minutes and plates were washed, TMB (Sigma Aldrich, Darmstadt, Germany) was added as a substrate and the optical density (OD) measured in a microplate absorbance spectrophotometer (Biorad, Hercules, CA, USA) at $450 \mathrm{~nm}$.

\section{Liposome Uptake, Cytokine Secretion and Maturation by Monocyte-Derived DC (moDC)}

Human peripheral blood mononuclear cells (PBMC) were isolated from buffy coats (Sanquin, Amsterdam, the Netherlands), as described before (17). Briefly, blood was mixed with $1 \%$ citrate-containing PBS, carefully layered on top of Lymphoprep (Alere Technologies AS, Oslo, Norway) and centrifuged for 30 minutes at $800 g$. Next, monocytes and lymphocytes were collected and washed in $1 \%$ citrate in PBS. In order to separate monocytes from contaminating lymphocytes, PBMC were added to a Percoll (GE Healthcare, Chicago, USA) layer and centrifuged for 10 minutes at $300 \mathrm{~g}$. Monocytes were collected and washed three times in $1 \%$ citrate in PBS. Subsequently, monocytes were resuspended in RPMI supplemented with 10\% FCS (Biowest, Manassas, VA, USA), 50 $\mathrm{U} / \mathrm{mL}$ penicillin (Lonza, Basel, Switzerland), $50 \mu \mathrm{g} / \mathrm{mL}$ streptomycin (Lonza, Basel, Switzerland) and $500 \mu \mathrm{g} / \mathrm{mL} \mathrm{IL-4}$ (ImmunoTools, Friesoythe, Germany) and $800 \mu \mathrm{g} / \mathrm{mL}$ Granulocyte Macrophage Colony stimulating Factor (GM-CSF) (ImmunoTools, Friesoythe, Germany) and cultured for 6 days to generate moDC. Where indicated, moDC were pretreated with type I interferon (IFN) $(100 \mathrm{IU} / \mathrm{mL}$, or dose as indicated in the figure) to upregulate the expression of CD169 on day 4. For liposome uptake and maturation moDC were plated and $100 \mu \mathrm{M}$ of phospholipid (diluted in full medium) were added to the moDC. After 45 minutes the cells were washed two to three times and resuspended in fresh medium. After 15-18 hours the supernatant was collected for an IL- $1 \beta$ ELISA, according to the manufacturers' protocol (Biolegend, San Diego, CA, USA), the cells were stained and analyzed as described under 'flow cytometry'. Where indicated, a CD169-blocking antibody (10 $\mu \mathrm{g} / \mathrm{ml}$ clone 7.239$)$ or an isotype control anti-Langerin $[10 \mu \mathrm{g} / \mathrm{ml}$ clone 10E2 (produced in house)], was added to the moDC 15 minutes prior to liposome incubation. For intracellular cytokine detection, moDC were plated and incubated with $100 \mu \mathrm{M}$ of phospholipid for 2 hours, subsequently cells were extensively 
washed and incubated in fresh medium for an additional 3 hours in the presence of Golgiplug, (BD, Bioscience, San Jose, CA, USA). Cells were then stained and analyzed as described under 'flow cytometry'. Individual donors were represented by individual data points in the figures.

\section{Animal Experiments}

C57BL/6 WT mice were bought from Charles River or bred in house. Male and female mice between 8 and 24 weeks of age were used for maturation studies. Female mice between 8 and 12 weeks were used for $\mathrm{T}$ cell priming experiments. These experiments were approved by the National Committee for Animal Experiments (CCD AVD1140020171024, 10 April 2017) and the local animal welfare body, Vrije Universiteit, Amsterdam UMC.

\section{In Vivo Maturation and T Cell Priming}

Mice were intravenously (i.v.) injected with liposomes (dose as indicated in figure legend, when not specified, $200 \mathrm{nmol}$ phospholipid). Where indicated, liposomes were replaced or supplemented with $25 \mu \mathrm{g}$ of poly IC (low molecular weight (LMW), Invivogen, Toulouse, France) and $25 \mu \mathrm{g}$ of activating anti-CD40 antibody (aCD40) (clone 1C10, produced in house), as positive control for DC maturation or T cell priming. Spleens were collected 16 hours or 7 days after the injection, for DC maturation or $\mathrm{T}$ cell priming, respectively. Splenocytes were either restimulated with short peptides for 5 or 25 hours [during the last 5 hours in the presence of Golgiplug, $\mathrm{BD}$, Bioscience, San Jose, CA, USA)], for $\mathrm{CD}^{+}$and $\mathrm{CD} 4^{+} \mathrm{T}$ cells, respectively and subsequently used for FACS analysis. Alternatively, splenocytes were directly used for flow cytometry analysis. Individual mice were indicated as single data points in the figures.

\section{Splenic Digestion}

Murine spleens were enzymatically digested when macrophages or DC were analyzed. Briefly, spleens were mechanically dissociated and digested in a mixture of $3 \mathrm{mg} / \mathrm{mL}$ lidocaine, $2 \mathrm{WU} / \mathrm{mL}$ Liberase TL (Roche, Mannheim, Germany) and $50 \mathrm{mg} / \mathrm{mL}$ DNase (Roche, Mannheim, Germany) for 12 minutes at $37^{\circ} \mathrm{C}$, while the mixture was continuously stirred. Next, ice-cold medium (RPMI-1640 (Gibco, Life Technologies, Paisley, UK) supplemented with 10\% FCS, 10 mM EDTA, 20 mM HEPES and $50 \mu \mathrm{M}$ 2-mercaptoethanol (Gibco, Life Technologies, Paisley, UK) was added, after which the digestion continued for 10 minutes at $4^{\circ} \mathrm{C}$. Red blood cells were lysed using an ammonium-chloride-potassium lysis buffer and remaining splenocytes were filtered through a 70-100 $\mu \mathrm{m}$ filter.

For $\mathrm{T}$ cell assays, spleens were mechanically dissociated by mashing the spleen through an 70-100 $\mu \mathrm{m}$ filter, after which red blood cells were lysed using an ammonium-chloride-potassium lysis buffer.

\section{In Vitro Liposome Incubation}

A single cell suspension of splenocytes was incubated with adjuvant-containing liposomes, $100 \mu \mathrm{M}$ phospholipid (diluted in full medium), or with soluble adjuvants (dose equal to $2 \mathrm{~mol} \%$ present in liposomes which is $5 \mu \mathrm{g} / \mathrm{mL}$ for TLR4L, $2 \mu \mathrm{g} / \mathrm{mL}$ for TLR7/8L, $2 \mu \mathrm{g} / \mathrm{mL}$ for PGPC or $3 \mu \mathrm{g} / \mathrm{mL}$ for MDP). After 45 minutes at $37^{\circ} \mathrm{C}$ splenocytes were extensively washed and surface stained (as described below), to asses liposome uptake. Alternatively, cells were extensively washed and incubated overnight at $37^{\circ} \mathrm{C}$ to mature, after which staining was performed.

\section{Flow Cytometry}

MoDC were washed and incubated with human Fc block (BD, Bioscience, San Jose, CA, USA) in the presence of the Fixable Viability Dye eFluor 780 (eBioscience, San Diego, CA, USA), diluted in $0.5 \%$ BSA in PBS. Next, moDC were stained with an anti-CD86 FITC conjugated antibody (clone BU63) (ImmunoTools, Friesoythe, Germany) for 30 minutes at $4^{\circ} \mathrm{C}$. Subsequently, cells were fixed in 2\% PFA (Electron Microscopy Sciences, Hatfield, PA, USA), washed and resuspended in $0.5 \%$ BSA in PBS until FACS analysis. When intracellular targets (IL$1 \beta$, clone REA577, Miltenyi Biotec, Leiden, the Netherlands) were analyzed, cells were washed in $0.5 \%$ saponin buffer after fixation and stained for 30 minutes at $4^{\circ} \mathrm{C}$.

A single cell suspension of splenocytes was incubated with 10 $\mu \mathrm{g} / \mathrm{mL}$ of Fc block (anti CD16/32, clone 2.4G2, produced in house) for 15 minutes with the Fixable Viability Dye eFluor 780, diluted in $0.5 \%$ BSA in PBS. If applicable, a tetramer staining (H$2 \mathrm{~K}^{\mathrm{b}} / \mathrm{OVA}_{257-264}$ (kindly provided by K.L. Franken, Dept of Immunology, LUMC) and I-A $\mathrm{O}^{\mathrm{b}} \mathrm{OVA}_{262-276}$ (kindly provided by the Tetramer core facility, National Institute of Health (NIH), Atlanta, GA, USA) was performed for 45 minutes at $37^{\circ} \mathrm{C}$, followed by a surface staining. Cells were surface stained with the antibodies listed below for 30 minutes at $4^{\circ} \mathrm{C}$ (Table 1). After surface staining, cells were fixed in $2 \%$ PFA. For staining of intracellular targets, cells were subsequently permeabilized with $0.5 \%$ saponin buffer and stained for 30 minutes at $4^{\circ} \mathrm{C}$ (Table $\mathbf{1}$ ).

\section{Statistical Analysis}

The statistical analysis was performed using GraphPad Prism v8 (GraphPad, San Diego, CA, USA). A one-tailed t-test was used to determine statistical differences between two groups. For three groups or more, a one-way ANOVA with a Tukey post-hoc test was used to determine statistical differences. Alternatively, when differences were compared to a control formulation, a Dunnett post-hoc test was used. When near significance was reached (i.e. a p-value of 0.1 , this was indicated). The p-value of 0.05 or lower was considered significant.

\section{RESULTS}

\section{Inclusion of TLR and Inflammasome Agonists Does Not Alter Physicochemical and CD169 Binding Properties of GM3 Liposomes}

In order to induce cellular maturation via liposomal adjuvant delivery, we used two different Toll-like receptor (TLR) agonists and two previously described inflammasome agonists $(52,55$, 56). We prepared two series of liposomes in which we combined 
TABLE 1 | Anti-mouse antibodies.

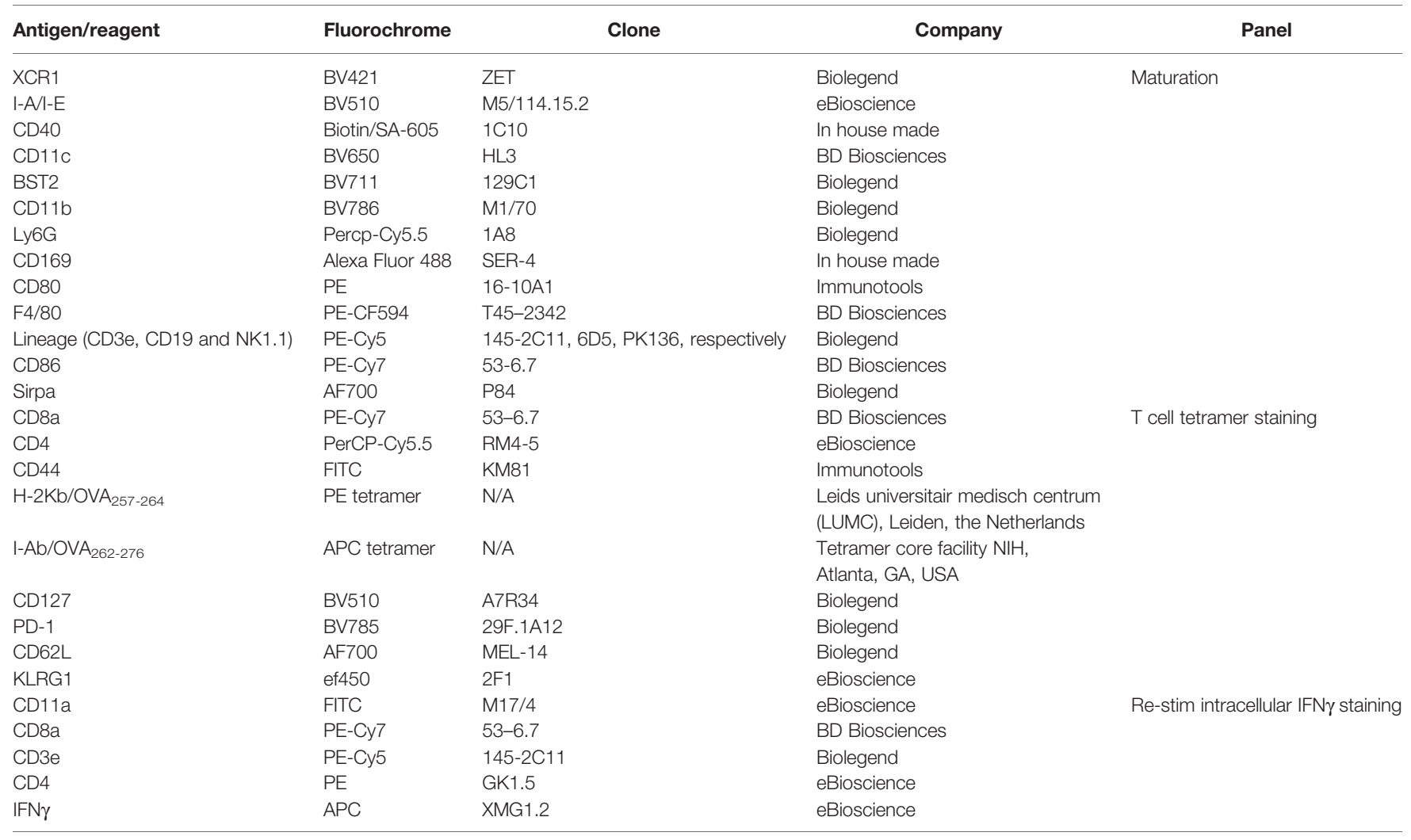

a TLR agonist (telratolimod/3M-052 for TLR7/8 or MPLA for TLR4) with the inflammasome stimulus oxidized lipid 1-palmitoyl2-glutaryl-sn-glycero-3-phosphocholine (PGPC), or nucleotidebinding oligomerization domain-containing protein 2 (NOD2) ligand L18-MDP (further referred to as MDP). Liposomes contained either one TLR ligand or a combination of one TLR ligand combined with one inflammasome stimulus. As controls, we prepared liposomes that did not contain any adjuvant (referred to as control), or contained only the oxidized lipid PGPC or only MDP (Supplementary Figures 1A, B). In addition, liposomes were without targeting ligand or contained the ganglioside GM3 (annotated with squares or circles, respectively) to facilitate specific uptake by CD169-expressing cells (18, 48, 49, 58, 59). The liposomes exhibited a similar mean size, in the range of 160$190 \mathrm{~nm}$ and a PDI below 0.2, indicating a relatively homogenous size distribution and the zeta-potential was negative, around -50 $\mathrm{mV}$ (Supplementary Figures 1A, B). All GM3 liposomes, but not the liposomes lacking GM3, bound to recombinant mouse CD169 in an ELISA-based assay (Figures 1A, C). We additionally investigated the binding of liposomes to the mutant form of mouse CD169 that contains an amino acid substitution (R97A), rendering it incapable of specific ligand binding (57). Since none of the formulations bound to the mutant form of CD169, we concluded that GM3 liposomes specifically bind CD169 (Figures 1A, C). Thus, adjuvant inclusion in liposomes did not alter the physicochemical properties of the liposomes and all GM3 liposomes bound specifically to CD169.

\section{TLR-Ligand-Containing GM3 Liposomes Bind to Human Monocyte-Derived Dendritic Cells and Induce Maturation}

GM3 liposomes bind to both human and mouse CD169expressing cells $(18,48,49,58,59)$. We first determined the capacity of the liposomes to be taken up and to activate human CD169-expressing APCs. We generated monocyte-derived dendritic cells (moDC) and where indicated, moDC were pretreated with $100 \mathrm{IU} / \mathrm{mL}$ type I IFN, to upregulate CD169 (58), which did not affect the expression of the maturation marker CD86 (Supplementary Figure 1C). We incubated liposomes with moDC for 45 minutes at $37^{\circ} \mathrm{C}$, and we included a blocking antibody to CD169 to determine the specificity for the CD169 receptor as moDCs also express other Siglec molecules (20). For both batches of liposomes, GM3 inclusion resulted in a higher ( $\sim 20$-fold) liposome uptake when compared to non-GM3-containing counterparts (gating according to Supplementary Figure 2A). As expected, pretreatment with a blocking antibody specific for CD169 abrogated the enhanced uptake of GM3 liposomes to background levels (Figures 1B, D). This reduction in uptake was not observed when we used an isotype control antibody (Supplementary Figure 1D). Unexpectedly we also observed some binding of TLR4L/MDP liposomes to moDC that was not blocked by the CD169 blocking antibody (Figure 1D).

Subsequently, we determined the ability of adjuvantcontaining GM3 liposomes to mature moDC. MoDC were 
A

- WT CD169

- Mutant CD169

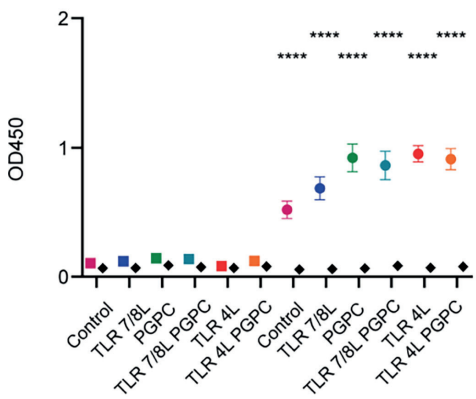

C

- WT CD169

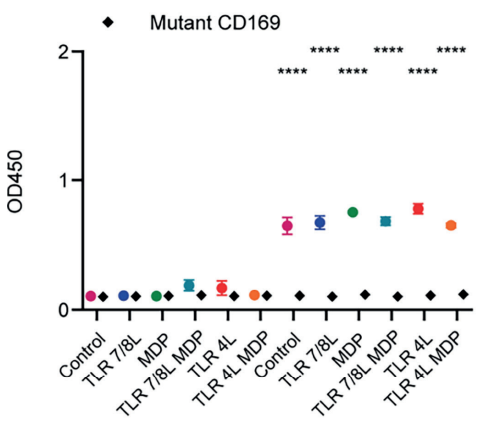

E

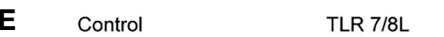

B

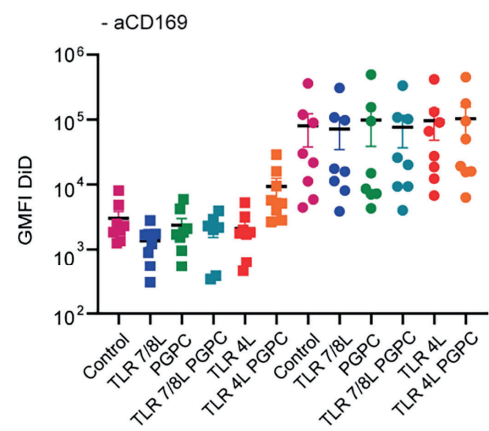

D

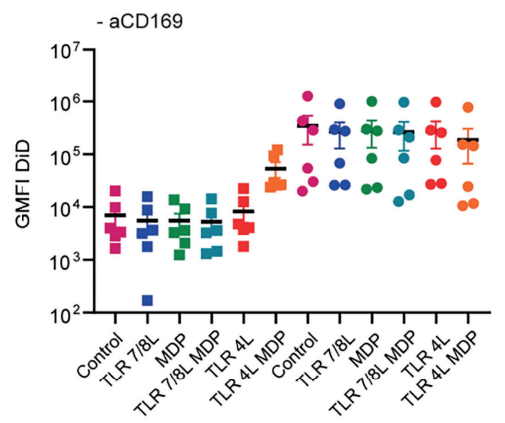

- Non GM3-containing

- GM3-containing

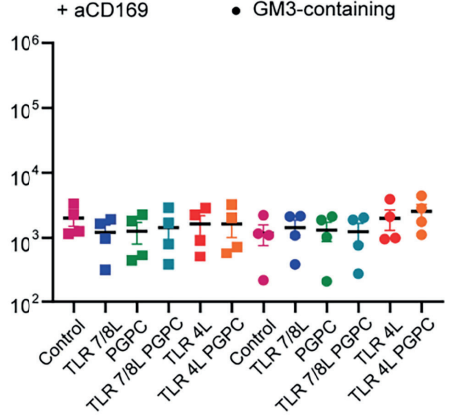

- Non GM3-containing

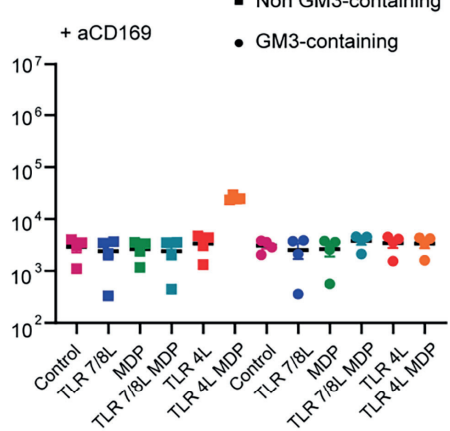

TLR 4L

TLR 4L PGPC

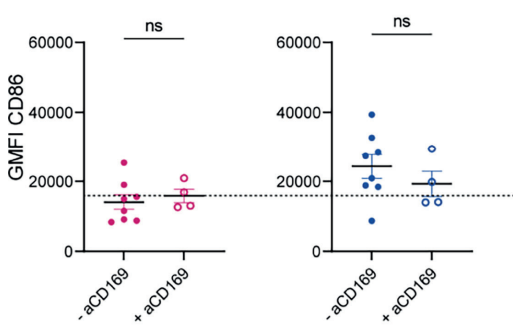

PGPC

TLR 7/8L PGPC

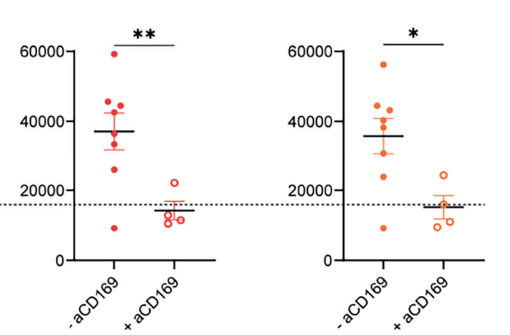

F Control

TLR 7/8L
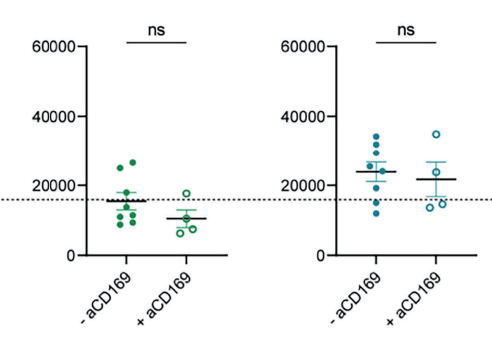

MDP

TLR 7/8L MDP

TLR 4L

TLR 4L MDP
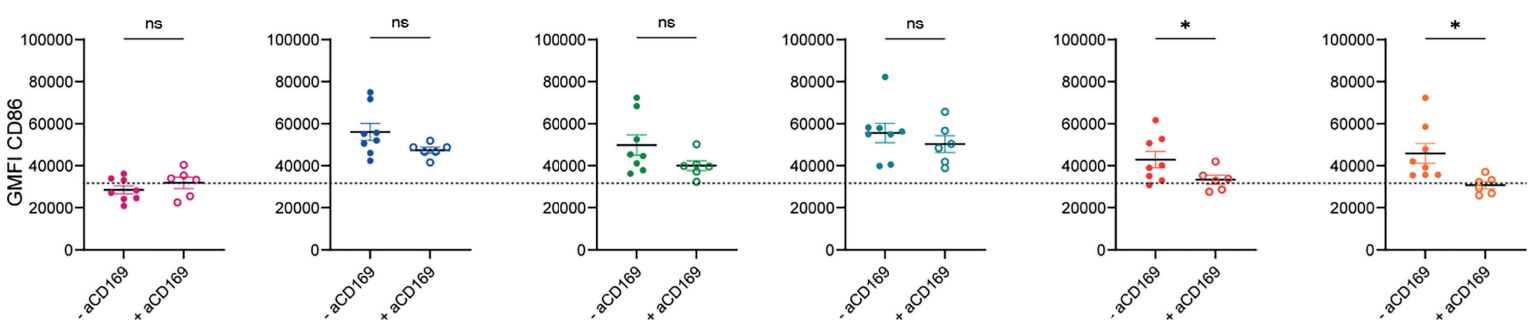

FIGURE 1 | Adjuvant inclusion in GM3 liposomes does not alter binding properties of liposomes and TLRL-inclusion induces moDC maturation. (A) Liposomes were coated on an ELISA plate and the organic solvent was evaporated overnight. Subsequently, binding to WT or mutant CD169 was determined. Indicated is the average \pm SEM of three independent experiments, performed in triplicate. Significance was compared to the non-GM3-containing counterpart. (B) Liposomes were incubated with moDC at $37^{\circ} \mathrm{C}$, that were untreated or pretreated with a blocking antibody 15 minutes prior to liposome incubation. Indicated is the average DiDsignal \pm SEM $(n=4-8)$. (C) As in A, indicated is the average \pm SEM of a technical triplicate. Significance was compared to the non-GM3-containing counterpart. (D) Liposomes were incubated with moDC (that were pretreated with type I IFN) at $37^{\circ} \mathrm{C}$, that were untreated or pretreated with a blocking antibody 15 minutes prior to liposome incubation. Indicated is the average DiD-signal \pm SEM $(n=4-6)$. (E) MoDC were non-treated or incubated with a blocking antibody for 15 minutes and subsequently incubated with liposomes for 45 minutes at $37^{\circ} \mathrm{C}$. Next, unbound liposomes were washed away and cells were incubated for $15-18 \mathrm{~h}$ at $37^{\circ} \mathrm{C}$, after which the cells were stained and the expression of CD86 was determined by flow cytometry analysis. Indicated is the average geometric mean fluorescent intensity (GMFI) of CD86 \pm SEM $(n=4-6)$. (F) as in E, but cells were pretreated with type I IFN (100 IU/mL). Indicated is the average GMFI of CD86 \pm SEM $(n=6-8)$. ${ }^{*} \mathrm{p}<$ $0.05,{ }^{* \star} p<0.01,{ }^{\star \star \star *} p<0.0001$. ns, not significant. 
either non-treated or treated for 15 minutes with a blocking antibody specific for CD169, prior to liposome incubation. Unbound liposomes were washed away and moDC were cultured overnight and stained for maturation markers. While GM3 liposomes without adjuvant (control) were not able to induce maturation (data not shown), GM3 liposomes harboring the ligands of TLR 4 or 7/8 were able to induce higher levels of the maturation marker CD86 (Figures 1E, F). While the oxidized lipid PGPC was not able to upregulate maturation, MDPcontaining GM3 liposomes did mature moDC (Figures 1E, F, respectively). We observed that the maturation induced by TLR4L was efficiently inhibited by the CD169-blocking antibody, but this was not observed for maturation induced by liposomes containing TLR7/8L and/or MDP (Figures 1E, F). In addition, we observed that TLR4L-containing GM3 liposomes induced IL-1 $\beta$ expression and secretion and that adjuvantcontaining GM3 liposomes were well tolerated, since excessive cell death upon stimulation was not observed (Supplementary Figures 1E-H). These results indicate that GM3 liposomes containing the TLR4L MPLA are more potent inducers of moDC maturation, when compared to GM3 liposomes containing TLR7/8L (3M-052) and/or MDP. We did not observe an effect on maturation upon PGPC incorporation in GM3 liposomes and PGPC or MDP in combination with TLRL did not result in higher maturation.

\section{GM3 Liposomes With Adjuvant Are Efficiently Taken Up by Mouse Splenic CD169-Macrophages and MPLA Inclusion Induces Robust DC Maturation}

Our previous studies have extensively demonstrated that GM3 liposomes bind to mouse splenic $\mathrm{CD} 169^{+}$macrophages, which in collaboration with $\mathrm{cDC} 1$ activate $\mathrm{T}$ cell responses $(48,49,60)$. In order to determine whether adjuvant-containing GM3 liposomes also effectively target to $\mathrm{CD} 169^{+}$macrophages and subsequently mature $\mathrm{CDC} 1$ and $\mathrm{CDC} 2$ we performed both in vitro as well as in vivo experiments that provided similar results [in vitro uptake and maturation (Supplementary Figure 3)]. In addition, we evaluated soluble adjuvants next to adjuvant-containing GM3 liposomes. The maturation induced by liposomal TLR4L was stronger compared to an equal soluble dose of TLR4L (Supplementary Figure 4A). Furthermore, both unformulated and GM3 liposome incorporated TLR7/8L induced maturation of DCs in vitro, albeit that maturation was variable and dependent on the readout (i.e. CD80 or CD86) (Supplementary Figure 4B). In contrast, PGPC or GM3 liposome incorporated PGPC did not induce DC maturation in vitro (Supplementary Figure 4B). To determine in vivo uptake, we immunized C57BL/6 mice intravenously (i.v.) with GM3 liposomes containing adjuvants. We observed that $16 \mathrm{~h}$ after i.v. immunization, all GM3 liposomes were effectively taken up by splenic $\mathrm{CD}_{169^{+}}$macrophages. Some uptake by conventional DC1 and DC2 was also observed, but these levels were extremely low compared to uptake by $\mathrm{CD} 169^{+}$macrophages (Figure 2A). Thus, adjuvant-containing GM3 liposomes effectively target $\mathrm{CD} 169^{+}$macrophages in vivo.
Next, we evaluated to what extent GM3 liposomes were able to mature $\mathrm{cDC} 1$ and $\mathrm{CDC} 2$ in vivo. GM3 liposomes that contained TLR4L were found to be highly effective in the maturation of $\mathrm{CDC1}$ and $\mathrm{CDC} 2$ (Figures 2B, C). Interestingly, adding PGPC to liposomal TLR4L, increased the expression of CD80 and CD86 on $\mathrm{CDC1}$ and $\mathrm{CDC} 2$, but did not affect the level of MHC class II and CD40 expression. This combined effect of PGPC plus TLR4L was observed in two independent experiments with two independent batches of liposomes [characteristics in (Supplementary Figure 5A)]. Immunization with GM3 liposomes containing TLR7/8L also resulted in DC maturation, but to a lower degree when compared to TLR4L. The addition of PGPC to TLR7/8L did not further enhance DC maturation (Figures 2B, C). Sole incorporation of PGPC did not elicit an effect as the level of maturation markers was similar to that of control GM3 liposomes immunized, and that of noninjected mice. Thus, TLR4L-containing GM3 liposomes efficiently mature DC in vivo and additional incorporation of PGPC increases the expression of CD80/86 on cDC1 and cDC2.

Subsequently, we performed a similar experiment with GM3 liposomes containing MDP, alone or in combination with TLR4 or TLR7/8 ligands. All GM3 liposomes containing adjuvant were found to be taken up by CD169-expressing macrophages, and to a significantly lower extent by $\mathrm{CDC1}$ and $\mathrm{CDC} 2$ (Figure 3A). Again, we observed efficient maturation of $\mathrm{cDC1}$ and $\mathrm{CDC} 2$ (based on MHC II, CD40 and CD80/86, or CD40 and CD80/86, respectively) when a TLRL was present (Figures 3B, C). While soluble or liposomal MDP induced maturation of $\mathrm{CDC} 2$ in vitro (Supplementary Figure 4B), sole inclusion of MDP tended to upregulate MHC II and CD40 in vivo, but did not affect CD80/86 and its overall effect was minor. This was observed with two independent batches in separate experiments (characteristics in Supplementary Figure 5B). In conclusion, incorporation of TLR4L (MPLA) in GM3 liposomes was most potent in inducing DC maturation, while TLRL7/8L (3M-052) was less potent. Addition of the inflammasome activators PGPC or MDP to TLRL containing GM3 liposomes resulted in only minor additional effects on maturation.

\section{Immunization With TLR4L-Containing GM3 Liposomes Induces Stronger T Cell Responses Compared to Immunization With TLR7/8L-Containing GM3 Liposomes}

Our next aim was to determine the capacity of the different liposomes to stimulate polyclonal $\mathrm{T}$ cell responses. Hence, adjuvant-containing GM3 liposomes were mixed with antigen-containing GM3 liposomes (in a 1:1 ratio). While the former liposomes were described above, the latter antigencontaining GM3 liposomes were described previously (49). Briefly, these GM3 liposomes had a mean size of $224 \pm 15.5$ $\mathrm{nm}$, a PDI of $0.2 \pm 0.05$, a mean zeta-potential of $-44.5 \mathrm{mV}$ and contained a synthetic long peptide derived from the model antigen ovalbumin $\left(\mathrm{OVA}_{247-279}\right)$. This peptide is immunogenic and contains both a CD4- and CD8-T cell epitope $\left(\mathrm{OVA}_{262-276}\right.$ and $\mathrm{OVA}_{257-264}$, respectively). Mixed liposomes or antigencontaining GM3 liposomes supplemented with soluble (i.e. not 
A

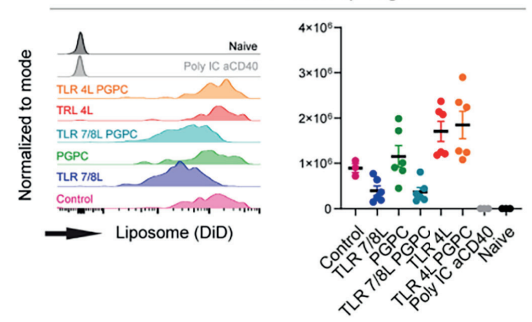

CDC1

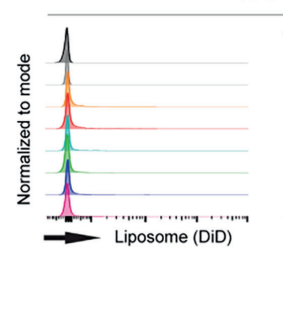

\section{1}

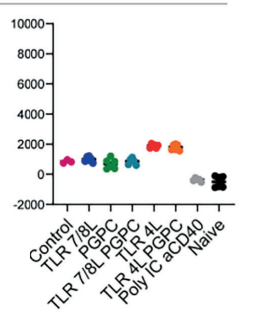

cDC1
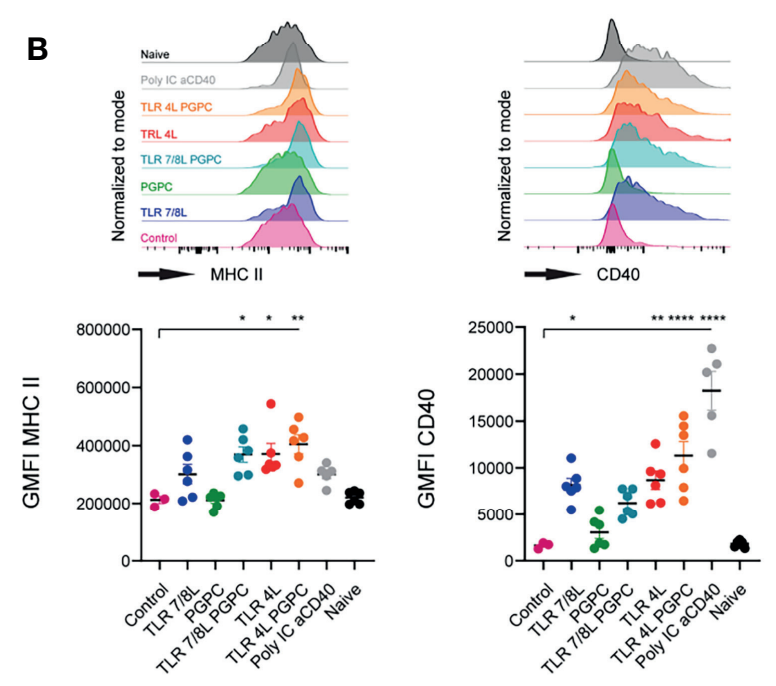
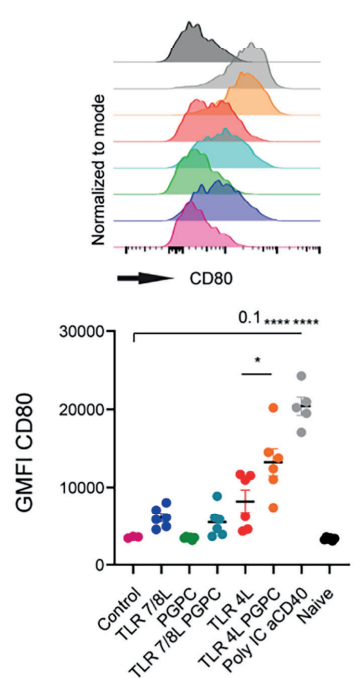

cDC2
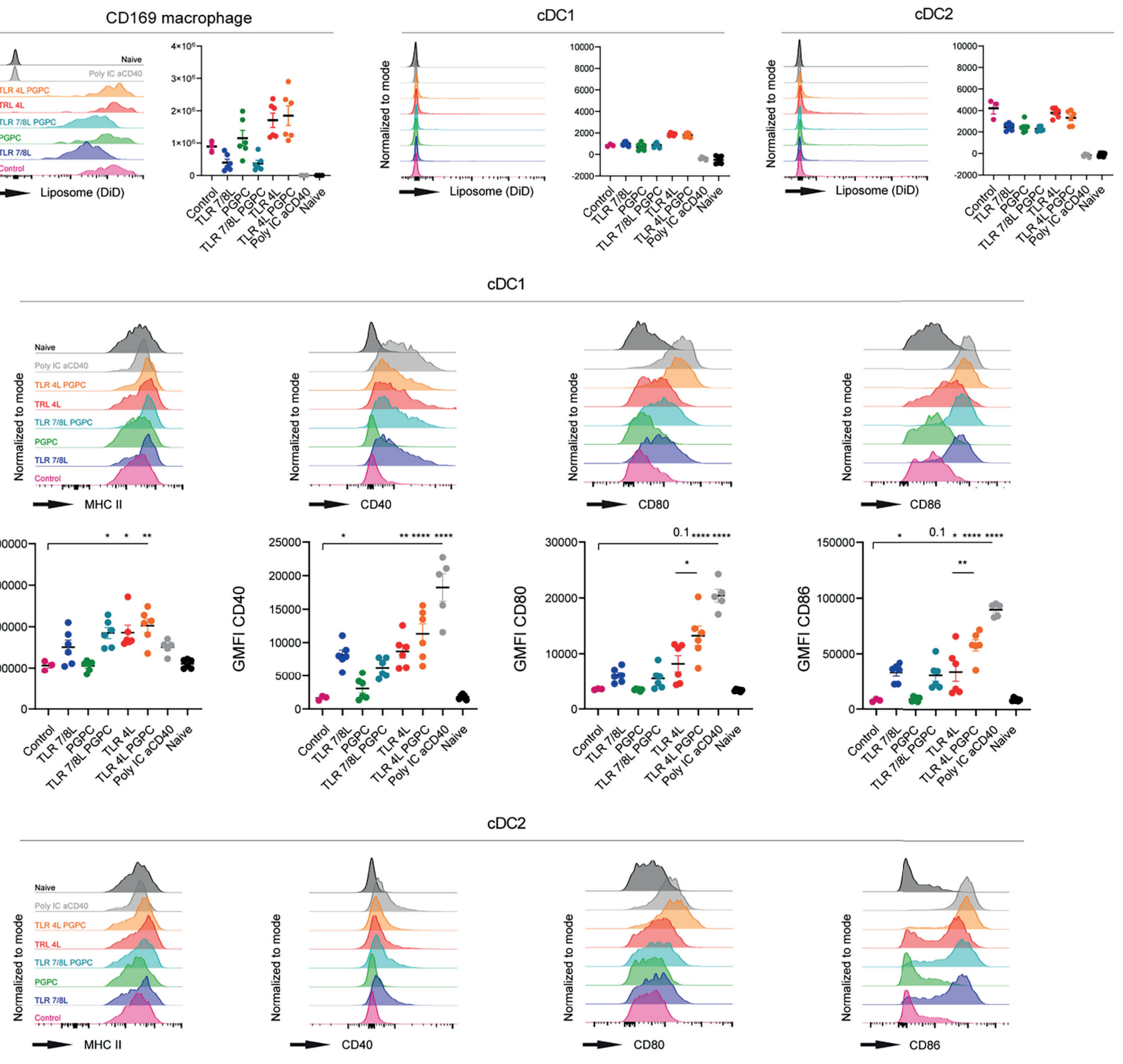

c
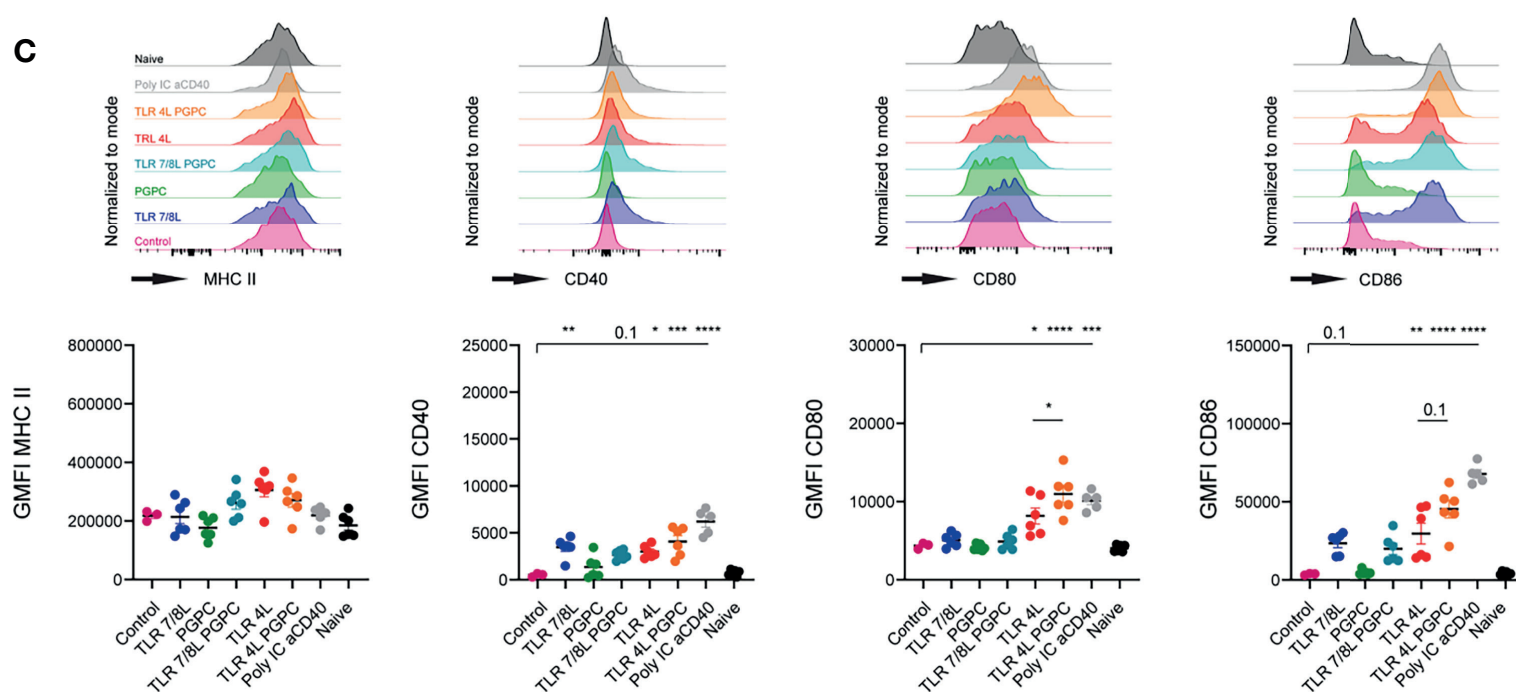

FIGURE 2 | TLRL-containing GM3 liposomes induce DC maturation in vivo, but additional incorporation of PGPC has minor effects. (A-C) Mice were i.v. injected with different liposomal formulations, poly IC and aCD40 antibody as positive control, or left uninjected (naive). 16h after injection, spleens were collected and a single cell suspension was used for flow cytometry staining and analysis. Indicated are representative histograms and the quantified DiD-signal as average \pm SEM, $[n=6$ ( $n=3$ for control liposome)], data pooled from two independent experiments (A). Indicated are representative histogram overlays and quantified average \pm SEM of maturation markers on cDC1 and cDC2 [(B, C), respectively) $\left[n=6\right.$ ( $n=3$ for control liposome)], data pooled from two independent experiments. ${ }^{\star} p<0.05$, ${ }^{* *} p<0.01,{ }^{* * *} p<0.005$ and ${ }^{* * * *} p<0.0001$. 
A

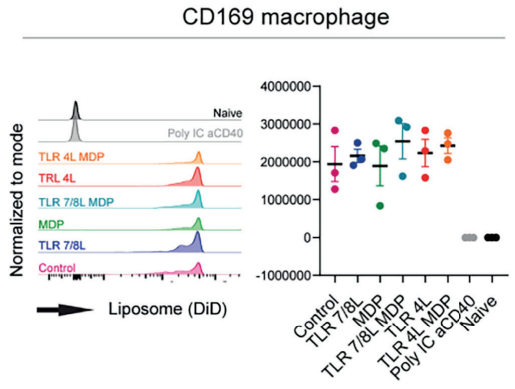

CDC1

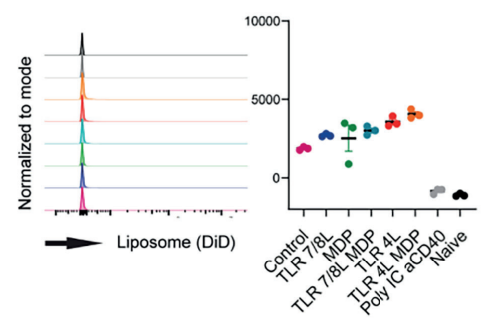

$\mathrm{cDC} 2$

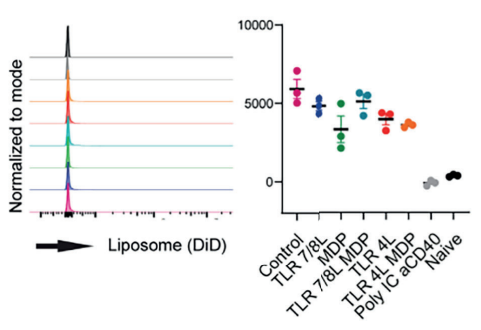

B

CDC1
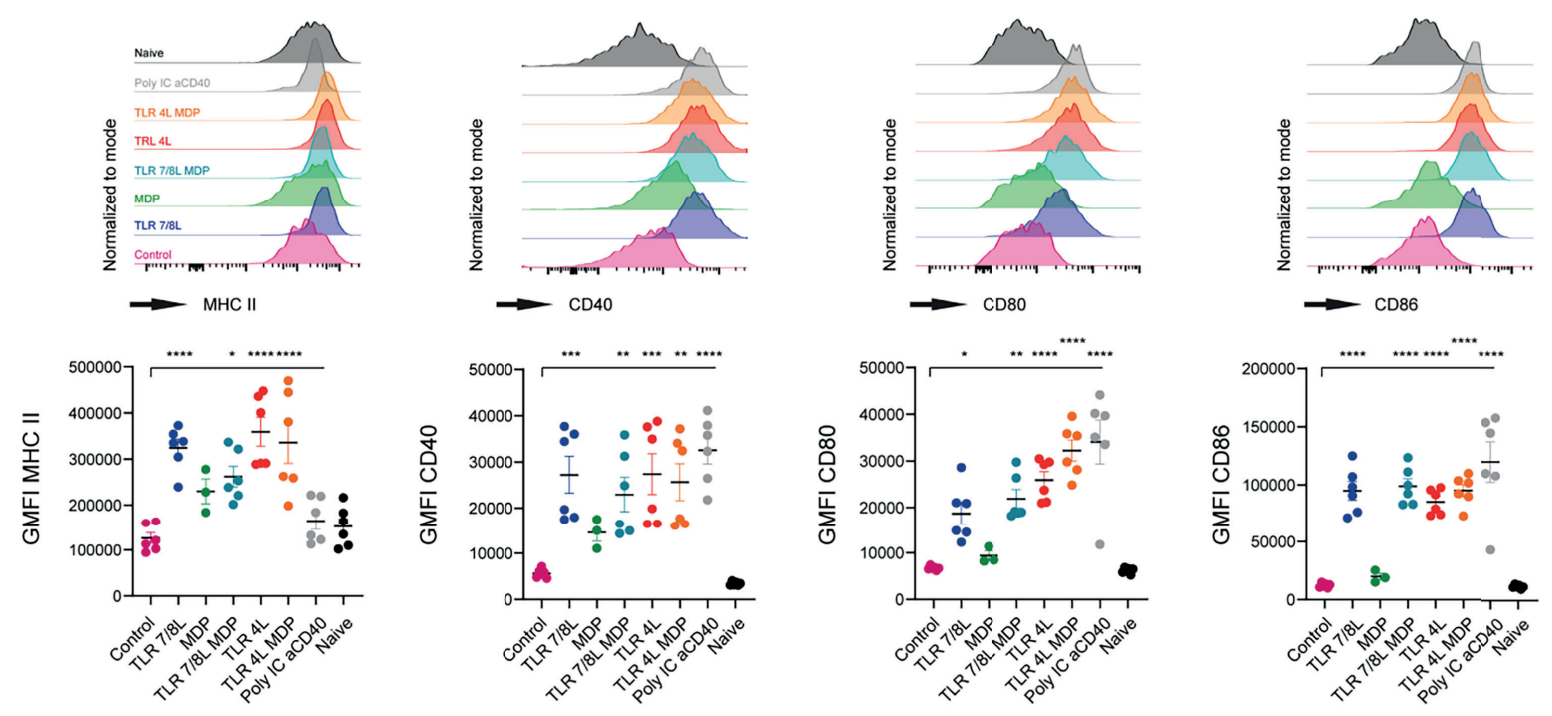

C

$\mathrm{CDC2}$
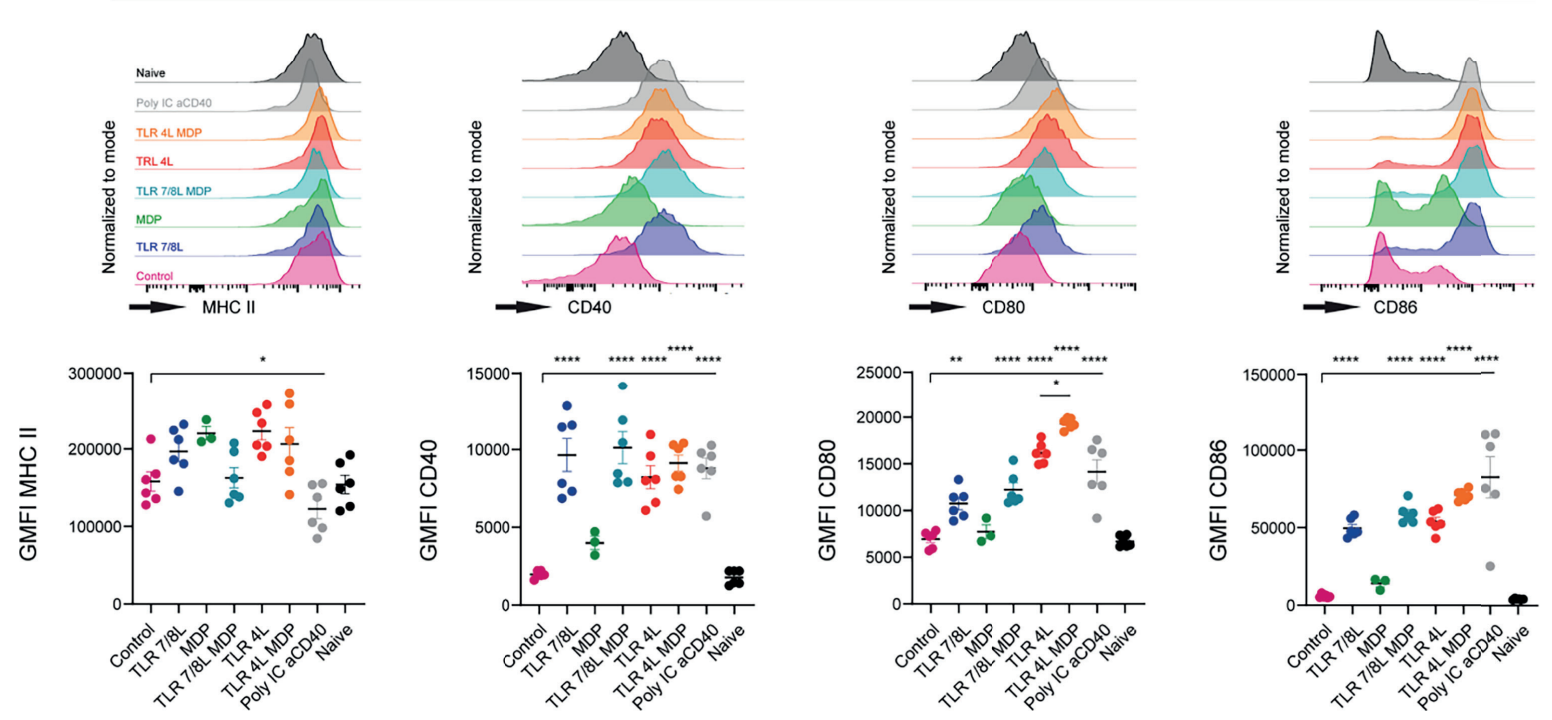

FIGURE 3 | TLRL-containing GM3 liposomes induce DC maturation in vivo and additional incorporation of MDP has no effect. (A-C) Mice were i.v. injected with different liposomal formulations, poly IC and aCD40 antibody as positive control, or left uninjected (naive). 16h after injection, spleens were collected and a single cell suspension was used for flow cytometry staining and analysis. Indicated are representative histogram overlays and the quantified DiD-signal as average \pm SEM $(n=3)$, representative of two independent experiments (A). Indicated are representative histogram overlays and quantified average \pm SEM of maturation markers on cDC1 and CDC2 [(B, C), respectively] $(n=3-6)$, data pooled from two independent experiments. ${ }^{\star} p<0.05,{ }^{* \star} p<0.01,{ }^{\star \star *} p<0.005$ and ${ }^{\star \star \star *} p<0.0001$. 
included in liposomes) adjuvant (aCD40 and poly IC) were administered i.v. to C57BL/6 mice. After 7 days, we analyzed the splenic compartment for the presence of antigen-specific $\mathrm{T}$ cells by intracellular IFN $\gamma$ staining after peptide restimulation (gating according to Supplementary Figure 2C). While immunization with GM3 liposomes containing TLR4L tended to result in stronger responses as compared to the GM3 liposomes with TLR7/8L, this was not significant. The highest $\mathrm{CD}^{+}$and $\mathrm{CD}^{+}{ }^{+}$responses were observed when we co-injected a strong soluble adjuvant as stimulus (Supplementary Figures 6A, B). As the overall responses in this experiment were relatively minor, we also mixed adjuvant- and antigencontaining GM3 liposomes in a 9:1 ratio. In addition, we included a control GM3 liposome that lacked a TLR ligand. Immunization with GM3 liposomes containing the ligand for TLR4 elicited more potent $\mathrm{T}$ cell responses as compared to GM3 liposomes with the ligand for TLR7/8, or control GM3 liposomes. In fact, TLR4L-containing GM3 liposomes were able to induce more robust $\mathrm{T}$ cell responses as compared to the control GM3 liposome, but TLR7/8L-containing GM3 liposomes failed to augment the response. The clear response elicited by TLR4L-containing GM3 liposomes was consistent with a more robust maturation observed with TLR4Lcontaining GM3 liposomes. However, the $\mathrm{T}$ cell responses induced by TLRL-containing GM3 liposomes were significantly lower than the response induced by the addition of a strong soluble adjuvant next to antigen-containing GM3 liposomes (Figures 4A, B).

\section{Addition of Inflammasome Ligands to TLR4L-Containing GM3 Liposomes Does Not Enhance Its Potency}

Immunization with antigen-containing liposomes supplemented with control or TLR7/8L-containing liposomes induced only low T cell responses. Thus, we continued with TLR4L-containing GM3 liposomes to assess the potential additional effect of the oxidized lipid PGPC and MDP on the T cell responses. Here, we incorporated the long synthetic $\mathrm{OVA}_{247-279}$ peptide in the adjuvant-containing GM3 liposomes, that were similar in size, PDI and zeta-potential as described above (Supplementary Figure 5A). One week after i.v. immunization, we analyzed antigen-specific $\mathrm{CD}^{+}$and $\mathrm{CD}^{+} \mathrm{T}$ cell responses by intracellular cytokine staining after peptide restimulation and tetramer staining (gating according to Supplementary Figures 2C, D, respectively). While we detected $\mathrm{T}$ cell responses after immunization with TLR4L-containing GM3 liposomes, the magnitude of the immune response, for both $\mathrm{CD} 8^{+}$and $\mathrm{CD} 4^{+} \mathrm{T}$ cells was lower when compared to the control group which we immunized with a strong soluble adjuvant (Figure 5A). In addition, we performed a high dimensionality reduction $t$ distributed stochastic neighbor embedding (tSNE) analysis on $\mathrm{H}-2 \mathrm{~K}^{\mathrm{b}} / \mathrm{OVA}_{257-264}$ specific $\mathrm{CD}^{+} \mathrm{T}$ cells and subsequently

A

Pregated on live single cell CD8+ T cells
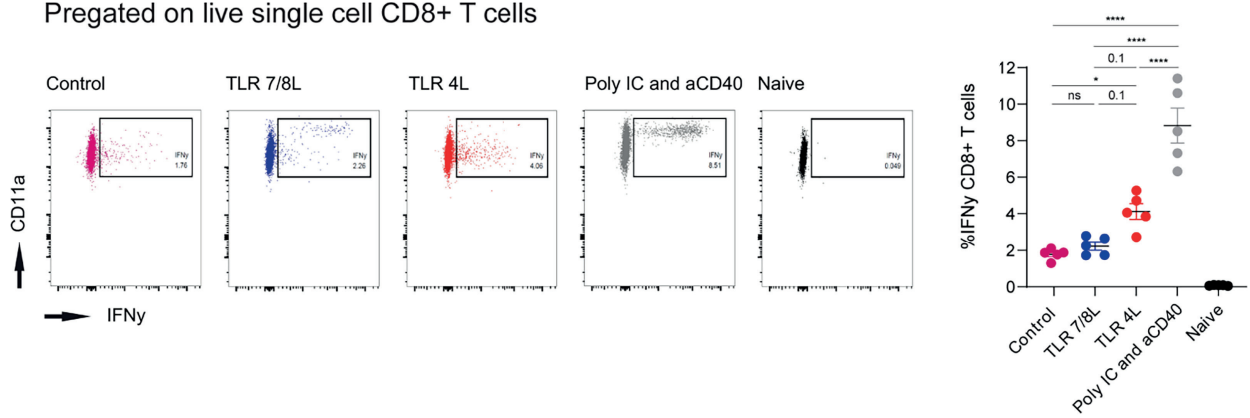

B Pregated on live single cell CD4+ T cells
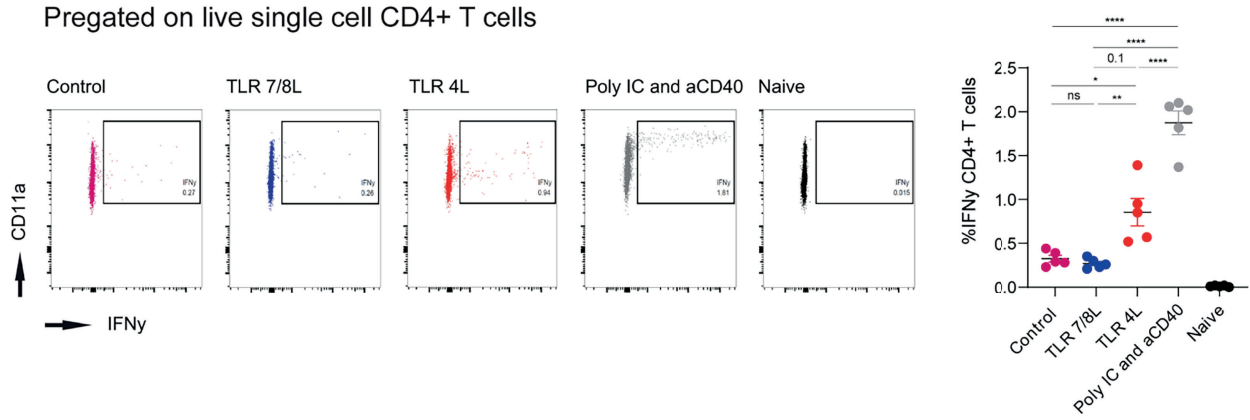

FIGURE 4 | Immunization with antigen-containing GM3 liposomes and TLR4L-containing GM3 liposomes elicits more robust antigen-specific immune responses than antigen-containing GM3 liposomes and TLR7/8L-containing GM3 liposomes. (A, B) Mice were i.v. immunized with antigen-containing GM3 liposomes (22.5 nmol phospholipid) that were supplemented with control GM3 liposomes (no TLR ligand), TLR7/8L-containing GM3 liposomes, TLR4L-containing GM3 liposomes (200 nmol phospholipid), or soluble poly IC and aCD40 antibody as positive control. After 7 days, spleens were collected and a single cell suspension was used for peptide restimulation for 5 or 25 hours for $\mathrm{CD}^{+}$and $\mathrm{CD}^{+} \mathrm{T}$ cells, respectively. Indicated are the representative dot plots of IFNy production after peptide restimulation and the average percentage \pm SEM of IFN $\gamma$-producing $C D 8^{+}$and CD4 ${ }^{+} T$ cells [(A, B), respectively] $(n=3-5) .{ }^{* \star} p<0.01$ and ${ }^{* \star \star *} p<0.0001 .{ }^{*} p<0.05$, ns, not significant. 

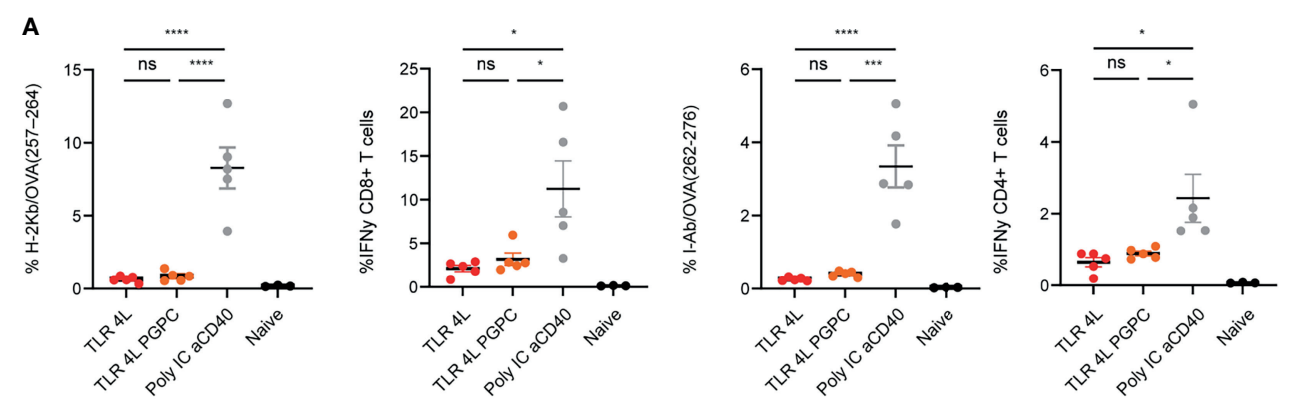

B $\mathrm{H}-2 \mathrm{~Kb} / \mathrm{OVA}(257-264)-\quad \mathrm{CD} 44$

CD62L

PD-1

KLRG1
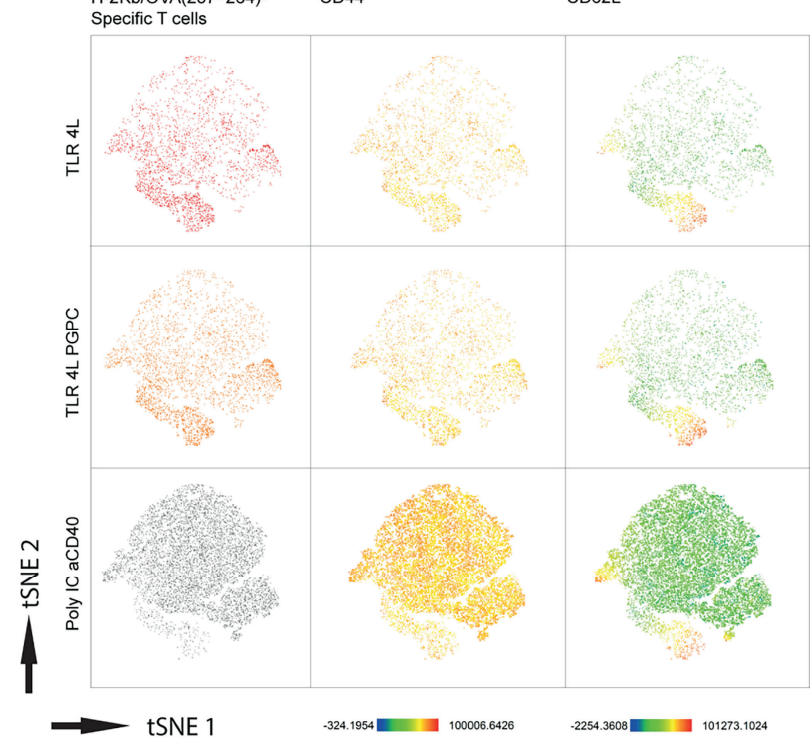

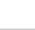
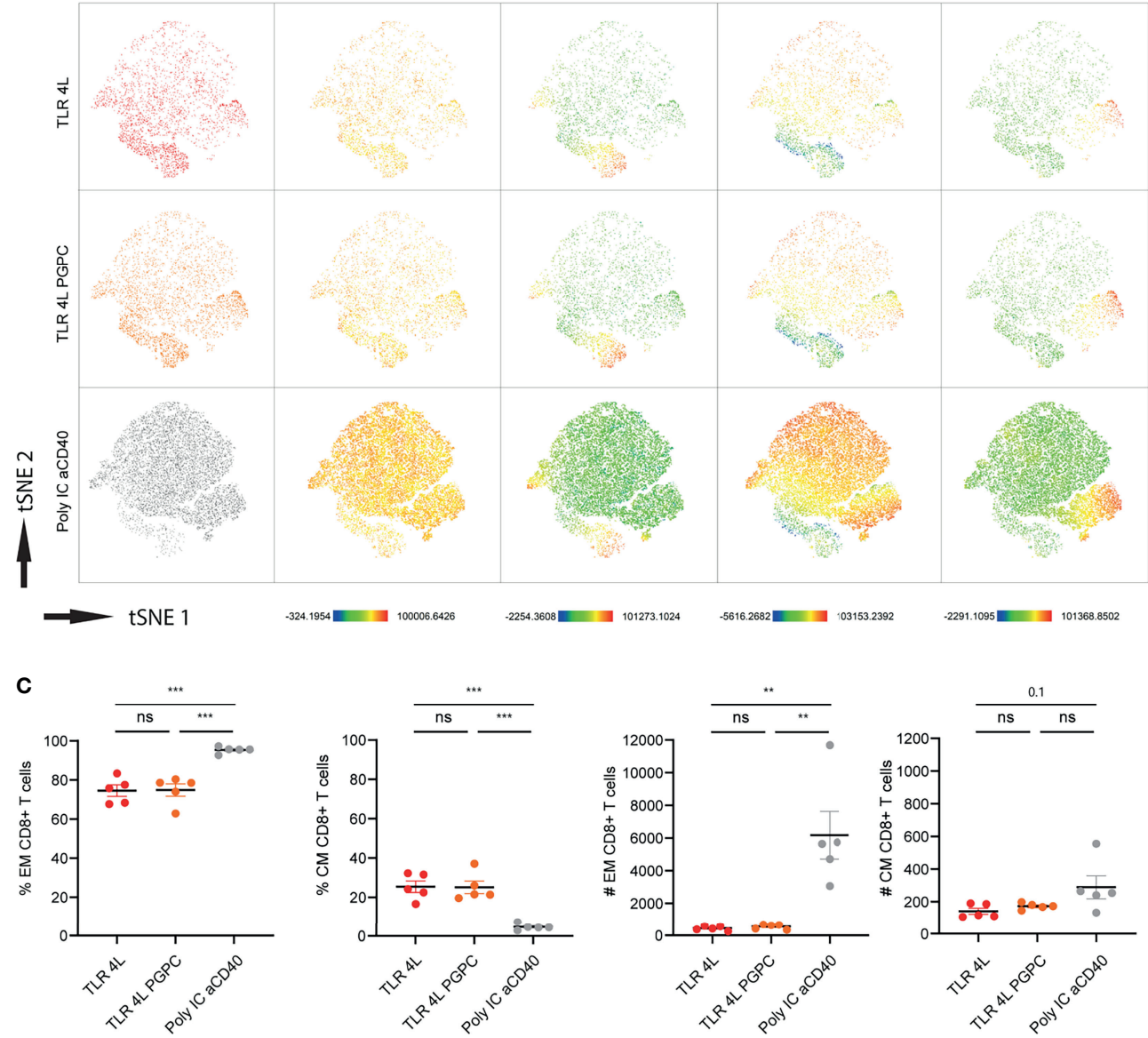

FIGURE 5 | Addition of PGPC does not augment the potency of TLR4L-containing GM3 liposomes. (A) Mice were i.v. injected with different liposome formulations, or antigen-containing liposomes with poly IC and aCD40 antibody as soluble adjuvant as a positive control, or left uninjected (naive). 7 days after injection, spleens were collected and a single cell suspension was used for tetramer staining or peptide restimulation. Indicated is the average \pm SEM of the percentage of IFN $\gamma$-producing $\mathrm{CD}^{+}$and $\mathrm{CD} 4^{+} \mathrm{T}$ cells upon peptide restimulation and $\mathrm{CD} 8^{+}$and $\mathrm{CD} 4^{+}$tetramer binding cells $(n=3-5)$. (B) $\mathrm{H}-2 \mathrm{~Kb} / \mathrm{OVA} 257-264$ binding T cells as identified in $\mathrm{A}$ were clustered using high-dimensional data reduction. $\mathrm{H}-2 \mathrm{~Kb} / \mathrm{OVA}_{257-264}$ binding $\mathrm{T}$ cells are indicated (groups were indicated with different colors in the first column), as well as their expression levels of CD44, CD62L, PD-1 and KLRG1. (C) H-2Kb/OVA $257-264$ binding T cells were subdivided in CD44 ${ }^{+}$Tem and $\mathrm{CD}_{4} 4^{+} \mathrm{CD} 62 \mathrm{~L}^{+} \mathrm{Tcm}$ cells. Indicated is the average $\pm \mathrm{SEM}$ of the percentage (of antigen-specific CD8 ${ }^{+} \mathrm{T}$ cells) and number of cells identified as Tem or Tcm (based on $10^{6}$ events) $(n=5) .{ }^{*} p<0.05,{ }^{* *} p<0.01,{ }^{* * *} p<0.005$ and ${ }^{* * *} p<0.0001$. ns, not significant.

subdivided previously concatenated populations into the different groups for unbiased phenotyping. Since immunization with a strong soluble adjuvant induced the strongest response, most events (antigen-specific CD8 ${ }^{+} \mathrm{T}$ cells) were present in this group (Figure 5B). Furthermore, we observed that immunization with
TLR4L-containing GM3 liposomes with or without PGPC resulted in a high abundance of $\mathrm{CD}_{4} 4^{+} \mathrm{CD}_{2} \mathrm{~L}^{-}$effector memory $\mathrm{T}$ cells $(\mathrm{Tem})$ and a population of $\mathrm{CD} 44^{+} \mathrm{CD} 2 \mathrm{~L}^{+}$ central memory $\mathrm{T}$ cells $(\mathrm{Tcm})$, of which the latter was higher in percentage as compared to the control with aCD40 and poly IC as 
strong soluble adjuvant, but similar in numbers (Figures 5B, C) [based on $10^{6}$ total events, the total number of splenocytes was similar between immunized groups (data not shown)]. The altered distribution between Tem and Tcm, but similar numbers of Tcm cells were also detected when we analyzed antigen-specific $\mathrm{CD} 4^{+} \mathrm{T}$ cells (Supplementary Figure 7B). Furthermore, immunization with a strong soluble adjuvant induced high expression of PD-1 on the Tem, while this was lower when we immunized with MPLA or MPLA/PGPC-containing GM3 liposomes (Figure 5B and Supplementary Figure 7A). We also detected a population of KLRG1-expressing Tem cells in all liposomal immunization strategies (Figure 5B and Supplementary Figure 7A). The additional incorporation of the inflammasome ligand PGPC in TLR4L-containing GM3 liposomes did not contribute to differences in the phenotype of antigen-specific $\mathrm{T}$ cells when compared to TLR4L-containing GM3 liposomes.

Next, we performed a similar experiment with TLR4Lcontaining GM3 liposomes with or without MDP. Consistent with our previous finding, TLR4L-containing GM3 liposomes induced antigen-specific $\mathrm{T}$ cell response, albeit lower when compared to our positive control (Figure 6A). The addition of the inflammasome stimuli MDP to TLR4L-containing GM3 liposomes did not augment the effect that was elicited by TLR4Lcontaining GM3 liposomes (Figure 6A). Furthermore, we performed a high dimensional data reduction on $\mathrm{H}-2 \mathrm{~K}^{\mathrm{b}} / \mathrm{OVA}_{257-}$ ${ }_{264}$ specific $\mathrm{CD}^{+} \mathrm{T}$ cells and subsequently analyzed the phenotype of these antigen-specific cells. We detected a robust induction of Tem cells upon immunization with a strong soluble adjuvant, that was less pronounced when we immunized with liposomal adjuvant (TLR4L with or without MDP), whereas the Tcm response differed less between the groups (Figures 6B, C) [based on $10^{6}$ total events, total number of splenocytes was similar in the immunized groups (data not shown)]. Again, this was also reflected by Tem and Tcm distribution within the antigen-specific $\mathrm{CD} 4^{+} \mathrm{T}$ cell compartment (Supplementary Figure 8B). In addition, immunization with a strong soluble adjuvant, aCD40 and poly IC, induced high levels of $\mathrm{PD}-1$ on antigen-specific $\mathrm{CD} 8^{+}$Tem cells. All vaccination strategies resulted in the presence of KLRG1-expressing Tem cells (Figure 6B and Supplementary Figure 8A). Thus, immunization with antigen and TLR4L-containing GM3 liposomes does translate into T cell responses, but robust expansion of Tem cells, as observed with a strong soluble adjuvant, was not detected.

In conclusion, TLRL delivery in GM3 liposomes results in maturation of both $\mathrm{CDC} 1$ and $\mathrm{CDC} 2$ and the activation of $\mathrm{T}$ cell responses. The additional inclusion of oxidized lipid PGPC or MDP had minor effects on DC maturation, and did not further enhance $\mathrm{T}$ cell priming. Our data indicate that adjuvant inclusion in GM3 liposomes is a viable strategy to induce DC maturation and $\mathrm{T}$ cell responses. Further studies will focus on different (combinations of) liposomal adjuvants to optimize $\mathrm{T}$ cell responses.

\section{DISCUSSION}

In this work, we build upon our previous observations that GM3targeted liposomes are effectively taken up by CD169-expressing human and mouse cells $(48,49,58,59)$, and that antigencontaining GM3 liposomes together with a strong soluble adjuvant (aCD40 and poly IC) can elicit potent immune activation and anti-tumor responses $(48,49)$. In our current study we aimed to utilize the versatile nature of liposomes to further augment the potency of liposomal cancer vaccination by inclusion of lipophilic adjuvants, which would remove the need for systemic administration of adjuvant. We incorporated ligands of TLR7/8 (3M-052) and TLR4 (MPLA) in GM3 liposomes and tested their potency alone, and in combination with inflammasome stimuli, the oxidized lipid PGPC or the NOD2 ligand MDP, to synergistically induce cellular maturation and subsequent $\mathrm{T}$ cell priming.

We detected robust human moDC maturation when TLR4L was incorporated into GM3 liposomes. The maturation by MPLA-containing GM3 liposomes was dependent on the presence of GM3 and binding to CD169. MPLA-containing GM3 liposomes also led to maturation of murine DCs and were more potent than a soluble dose of MPLA. In contrast, GM3 liposomes containing TLR7/8L were less stimulatory and blocking of CD169 did not inhibit maturation induced by TLR7/ $8 \mathrm{~L}$ or MDP liposomes as effective. Indeed, while the TLR7/8L in this study contains hydrophobic regions that allow for its incorporation in the liposomal bilayers (61), this ligand may not be as stably embedded in the bilayer as MPLA that contains six acyl chains. Similarly, the NOD2 ligand used in this study contains a single lipid tail (62), which may indicate a relatively weak interaction with the liposomal bilayers and potential release from the liposomes. Our data are very similar to those obtained by Boks and coworkers which targeted adjuvant-containing Lewis X-liposomes to DC-SIGN on moDC (16). In this study, maturation induced by TLR4L-containing Lewis X-liposomes was also dependent on the presence of targeting moieties and could be blocked with a blocking DC-SIGN antibody. Maturation induced by TLR7/8L-containing Lewis X-liposomes was less dependent on Lewis X mediated targeting and induced maturation was less sensitive to a blocking antibody (16). These data together with ours indicate that the combination of TLR4L and a targeting ligand leads to the most optimal DC maturation and appears to be a valid approach to augment the potency of liposomal cancer vaccines.

We additionally included the oxidized lipid PGPC in our liposomal formulations to aim for a synergistic or additive effect on DC maturation and subsequent $\mathrm{T}$ cell responses. While synergistic effects of oxidized lipids next to TLR4L stimulation was previously observed (52), we failed to see strong effects. There are a few important considerations that may explain this difference. First, while Zhivaki and coworkers temporally spaced their stimuli and first primed with a TLR4L followed by PGPC, we incorporated both TLR4L and PGPC in the same particles. Furthermore, other studies also described suppressing effects of oxidized lipids. Pretreatment of cells with oxidized lipids reduced subsequent LPS-mediated maturation (63) and simultaneous treatment with certain species of oxidized lipids with LPS diminished LPS-induced cytokine secretion (64). Thus, the tissue context and timing of exposure to TLR ligands/oxidized 

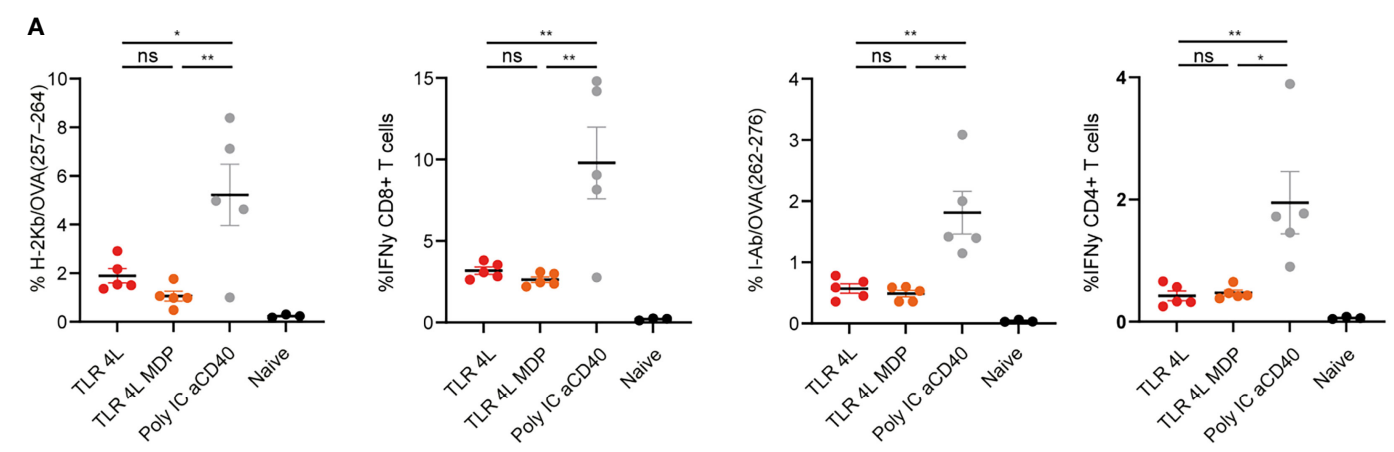

\section{B}

H-2Kb/OVA(257-264)-

CD44

CD62L

PD-1

KLRG1
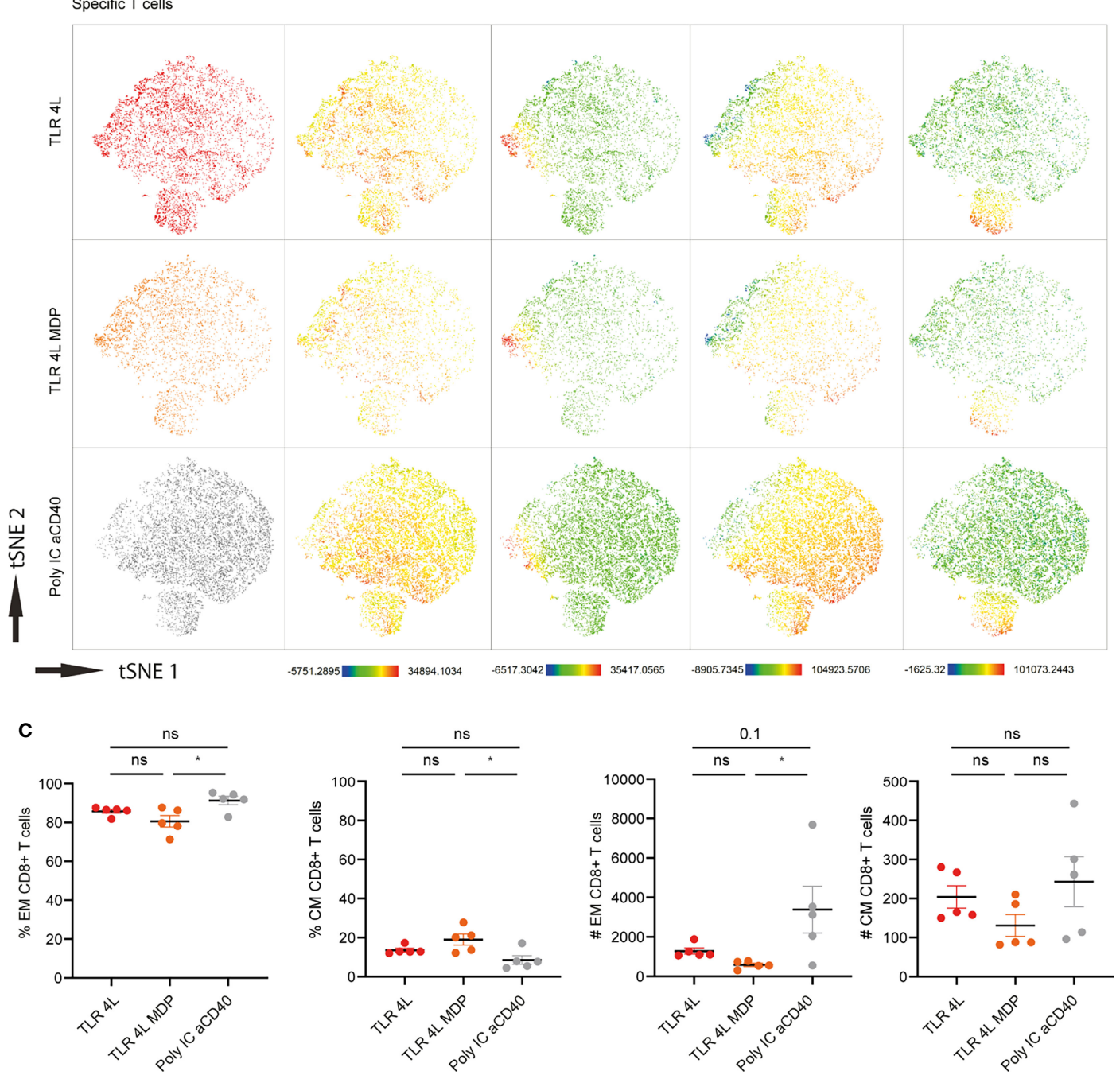

FIGURE 6 | Addition of MDP does not augment the potency of TLR4L-containing GM3 liposomes. (A) Mice were i.v. injected with different liposome formulations, or antigen-containing liposomes with poly IC and aCD40 antibody as soluble adjuvant as a positive control, or left uninjected (naive). 7 days after injection, spleens were collected and a single cell suspension was used for tetramer staining or peptide restimulation. Indicated is the average \pm SEM of the percentage of IFN $\gamma-$ producing $\mathrm{CD}^{+}$and $\mathrm{CD} 4^{+} \mathrm{T}$ cells upon peptide restimulation and $\mathrm{CD} 8^{+}$and $\mathrm{CD} 4^{+}$tetramer binding cells $(n=3-5)$. (B) $\mathrm{H}-2 \mathrm{~Kb} / \mathrm{OVA} \mathrm{A}_{257-264}$ binding $\mathrm{T}$ cells as identified in $\mathrm{A}$ were clustered using high-dimensional data reduction. $\mathrm{H}-2 \mathrm{~Kb} / \mathrm{OVA} \mathrm{A}_{257-264}$ binding $\mathrm{T}$ cells are indicated phenotyping (groups were indicated with different colors in the first column) as well as their expression levels of CD44, CD62L, PD-1 and KLRG1. (C) $\mathrm{H}-2 \mathrm{~Kb} / \mathrm{OVA}_{257-264}$ binding $\mathrm{T}$ cells were subdivided in $\mathrm{CD}_{4}{ }^{+} \mathrm{Tem}$ and $\mathrm{CD}_{4} 4^{+} \mathrm{CD} 62 \mathrm{~L}^{+} \mathrm{Tcm}$ cells. Indicated is the average $\pm \mathrm{SEM}$ of the percentage (of antigen-specific CD8 ${ }^{+} \mathrm{T}$ cells) and number of cells identified as Tem or Tcm (based on $10^{6}$ events) $(n=5)$. ${ }^{*} \mathrm{p}<0.05$ and ${ }^{* *} \mathrm{p}<0.01$. ns, not significant. 
lipids appears to be an important determinant of subsequent cytokine secretion and cellular maturation. Second, the effect of oxidized lipids may also depend on the recipient cell type, as DC generated with granulocyte-macrophage colony-stimulating factor (GM-CSF) were more sensitive to oxidized lipids as compared to conventional fms-like tyrosine kinase 3 liganddependent DC (54). More detailed, the bone marrow-derived DC model consist of a mixed population of monocyte-derived macrophages and DC and inflammasome ligands elicited more robust responses in GM-CSF-derived macrophages than GMCSF-derived DC (65). The requirement of CD14 expression to elicit an effect of oxidized lipid may explain differences observed between the heterogeneous mixture of cells generated from the bone marrow with GM-CSF and conventional (splenic) DC (66). In addition, expression of IRF8 and IRF4, by $\mathrm{CDC1}$ and $\mathrm{CDC} 2$, respectively, was associated with reduced inflammasome activation (67). Thus, targeting of liposomal vaccine components to monocyte-derived cells may result in stronger inflammasome-mediated responses as compared to those elicited by targeting to conventional DC. Third, as we aimed to administer the oxidized lipids in liposome-embedded form we were limited with regard to the dose of PGPC. While we started with a dose of $2 \mathrm{~mol} \%$ of liposomal PGPC, we later also tested a higher dose of $5 \mathrm{~mol} \%$. However, this did not result in stronger effects as compared to those elicited by $2 \mathrm{~mol} \%$ liposomal PGPC (data not shown). Incorporation of an even higher dose of PGPC in liposomes may result in micelle formation (68). Therefore, we did not attempt to prepare liposomes containing a higher amount of PGPC that would enable the administration of the same dose of PGPC, as used by others (52). While liposomal delivery of cargo was expected to augment immunological effects compared to the administration in non-liposomal form, we observed only minor effects on maturation caused by the liposomal oxidized lipid (combined with TLR4L) and in addition, this did not translate to enhanced $\mathrm{T}$ cell responses. Therefore, the potential beneficial use of PGPC in liposomal cancer vaccine immunization requires further investigation of mechanisms of delivery to find conditions in which stronger synergistic effects can be achieved.

There is a long-standing interest in liposomal muramyl (tri) peptides for inducing immune activation $(69,70)$. Recently, renewed interest in MDP sparked, as it was shown to induce a state of DC hyperactivity, when combined with TLR ligands (55, 56). Indeed, stimulation of human $\mathrm{CDC} 2$ at different time points with TLR7/8L and MDP led to potent cytokine secretion in vitro (56). In addition, incubation with nanoparticles containing MDP and TLR7/8L induced additive murine DC maturation in vitro. While the effect on bone marrow-derived DC was robust, the effect on primary isolated splenic DC was less pronounced (55). We detected responses to liposomal TLR7/8 ligand stimulation in vitro, but failed to see a robust additive effect of liposomal MDP in vitro and in vivo. Indeed, this may be a consequence of the cell types we studied, since, similar as discussed above for PGPC, bone marrow-derived DC (stimulated with GM-CSF) were better responders as compared to primary splenic conventional DC (55). While incorporation of MDP alone elicited some effect on DC maturation, this effect was not as potent as in the case of liposomal TLR ligands. Further research should focus on temporally spaced administration of these different liposomes in different concentrations to optimize synergistic DC maturation and subsequent $\mathrm{T}$ cell responses.

Next to DC maturation, we aimed to assess to what extent matured DC prime T cells upon liposomal immunization. We previously used liposomes together with soluble poly IC and activating anti-CD40 antibody as adjuvant for immunization (48, 49). In order to search for immunization strategies with less systemic side effects, we assessed various liposomal adjuvants and took along poly IC and aCD40 antibody as positive control. While immunization with antigen and TLRL-containing GM3 liposomes did translate into $\mathrm{T}$ cell responses, the magnitude was lower as compared to poly IC and aCD40 antibody administrated as soluble adjuvants. In addition, we detected a robust expansion of Tem cells upon immunization with GM3 liposomes supplemented with a strong soluble adjuvant that was not observed when we immunized with TLR4L-containing GM3 liposomes. Remarkably, the numbers of Tcm cells after immunization with GM3 liposomes supplemented with a aCD40 and poly IC were similar to those induced by TLR4Lcontaining GM3 liposomes. This observation is based on the relatively simple distinction between antigen-specific Tem cells $\left(\mathrm{CD} 44^{+}\right)$and $\mathrm{Tcm}$ cells $\left(\mathrm{CD} 44^{+} \mathrm{CD} 62 \mathrm{~L}^{+}\right)$, thus limiting the possible appreciation of $\mathrm{Tcm}$ cell heterogeneity (71). The formation of Tcm cells was described to depend on the duration of antigenic stimuli, and less dependent on the inflammatory status of the immune system (72). In addition, $\mathrm{Tcm}$ exhibited a lower proliferative index as compared to Tem (72). Consistent with these observations, we observed that the absolute numbers of $\mathrm{CD}^{+}$and $\mathrm{CD} 4^{+} \mathrm{Tcm}$ cells were comparable when we immunized with GM3 liposomes supplemented with soluble aCD40 and poly IC or TLR4L-containing GM3 liposomes. While the inflammatory status of the immune system after immunization with liposomal TLRL will likely be lower when compared to soluble poly IC and aCD40 antibody, antigen presentation is expected to be similar, explaining the similar numbers of Tcm observed in our immunization strategy. Further research should elucidate whether the use of different types and combinations of adjuvant induce differences in memory responses after a second boost of antigen.

In conclusion, our study demonstrates that GM3 liposomes can be used for co-delivery of adjuvant and antigen. TLR4L-containing GM3 liposomes are able to mature DCs and induce $\mathrm{CD} 4^{+}$and $\mathrm{CD}^{+} \mathrm{T}$ cell priming. Further research into different combinations of adjuvants incorporated in GM3 liposomes will be necessary to achieve optimal effects upon immunization. Thus far, our results clearly support the development of liposomal vaccination platforms to stimulate anti-cancer immune responses.

\section{DATA AVAILABILITY STATEMENT}

The raw data supporting the conclusions of this article will be made available by the authors, without undue reservation. 


\section{ETHICS STATEMENT}

The animal study was reviewed and approved by National Committee for Animal Experiments, Vrije Universiteit, Amsterdam UMC.

\section{AUTHOR CONTRIBUTIONS}

The project conceptualization was performed by MN, LC, GS, and JH. MN, LC, RB, KO, JG, AW, AA, and SB carried out the experiments, that were analyzed by $\mathrm{MN}$. Materials were provided by $\mathrm{HK}$ and supervision provided by $\mathrm{CN}, \mathrm{YK}, \mathrm{GS}$, and JH. The initial manuscript draft was prepared by $\mathrm{MN}$ and $\mathrm{JH}$, remaining authors reviewed and edited the manuscript. All authors contributed to the article and approved the submitted version.

\section{FUNDING}

This work was supported by grants from NWO ZonMW (TOP 91218024) to JH and GS, grants from the Dutch Cancer Society

\section{REFERENCES}

1. Alexandrov LB, Nik-Zainal S, Wedge DC, Aparicio SAJR, Behjati S, Biankin $\mathrm{AV}$, et al. Signatures of Mutational Processes in Human Cancer. Nature (2013) 500(7463):415-21. doi: 10.1038/nature12477

2. Haen SP, Löffler MW, Rammensee HG, Brossart P. Towards New Horizons: Characterization, Classification and Implications of the Tumour Antigenic Repertoire. Nat Rev Clin Oncol (2020), 1-16. doi: 10.1038/s41571-020-0387-x

3. Melief CJ, van Hall T, Arens R, Ossendorp F, van der Burg SH. Therapeutic Cancer Vaccines. J Clin Invest (2015) 125(9):3401-12. doi: 10.1172/JCI80009

4. Wolchok JD, Chiarion-Sileni V, Gonzalez R, Rutkowski P, Grob J-J, Cowey $\mathrm{CL}$, et al. Overall Survival With Combined Nivolumab and Ipilimumab in Advanced Melanoma. N Engl J Med (2017) 377(14):1345-56. doi: 10.1056/ NEJMoa1709684

5. Ribas A, Wolchok JD. Cancer Immunotherapy Using Checkpoint Blockade. Science (2018) 359(6382):1350-5. doi: 10.1126/science.aar4060

6. Sahin U, Türeci Ö. Personalized Vaccines for Cancer Immunotherapy. Science (2018) 359(6382):1355-60. doi: 10.1126/science.aar7112

7. Finn OJ. The Dawn of Vaccines for Cancer Prevention. Nat Rev Immunol (2018) 18(3):183-94. doi: 10.1038/nri.2017.140

8. Saxena M, van der Burg SH, Melief CJM, Bhardwaj N. Therapeutic Cancer Vaccines. Nat Rev Cancer (2021) 21(6):360-78. doi: 10.1038/s41568-02100346-0

9. Gardner A, Ruffell B. Dendritic Cells and Cancer Immunity. Trends Immunol (2016) 37(12):855-65. doi: 10.1016/j.it.2016.09.006

10. Joffre OP, Segura E, Savina A, Amigorena S. Cross-Presentation by Dendritic Cells. Nat Rev Immunol (2012) 12(8):557-69. doi: 10.1038/nri3254

11. Alloatti A, Kotsias F, Pauwels A-M, Carpier J-M, Jouve M, Timmerman E, et al. Toll-Like Receptor 4 Engagement on Dendritic Cells Restrains PhagoLysosome Fusion and Promotes Cross-Presentation of Antigens. Immunity (2015) 43(6):1087-100. doi: 10.1016/j.immuni.2015.11.006

12. Nair-Gupta P, Baccarini A, Tung N, Seyffer F, Florey O, Huang Y, et al. TLR Signals Induce Phagosomal MHC-I Delivery From the Endosomal Recycling Compartment to Allow Cross-Presentation. Cell (2014) 158(3):506-21. doi: 10.1016/j.cell.2014.04.054

13. Takeda K, Akira S. Toll-Like Receptors. Curr Protoc Immunol (2015) 109:14.12.1-14.12.10. doi: 10.1002/0471142735.im1412s109

14. Amon L, Hatscher L, Heger L, Dudziak D, Lehmann CHK. Harnessing the Complete Repertoire of Conventional Dendritic Cell Functions for Cancer
(VU2016-10449), from the Phospholipid Research Center (JDH2020-082/1-1), from Health Holland TKI-PPP to JH and a grant from the NUS School of Medicine Nanomedicine Research Programme (NUHSRO/2021/034/TRP/09/Nanomedicine) to GS.

\section{ACKNOWLEDGMENTS}

We hereby thank the Microscopy and Cytometry Core Facility at the Amsterdam UMC - Location VUmc for excellent assistance in flow cytometry. We also thank employees of the Vrije Universiteit animal facility for assistance. In addition, we thank the NIH tetramer core facility for providing the $\mathrm{I}-\mathrm{A}^{\mathrm{b}} /$ $\mathrm{OVA}_{262-276}$ tetramer.

\section{SUPPLEMENTARY MATERIAL}

The Supplementary Material for this article can be found online at: https://www.frontiersin.org/articles/10.3389/fimmu.2022. 842241/full\#supplementary-material

Immunotherapy. Pharmaceutics (2020) 12(7):663. doi: 10.3390/ pharmaceutics12070663

15. Allen TM, Cullis PR. Liposomal Drug Delivery Systems: From Concept to Clinical Applications. Adv Drug Deliv Rev (2013) 65(1):36-48. doi: 10.1016/ j.addr.2012.09.037

16. Boks MA, Ambrosini M, Bruijns SC, Kalay H, van Bloois L, Storm G, et al. MPLA Incorporation Into DC-Targeting Glycoliposomes Favours AntiTumour T Cell Responses. J Cont Rel (2015) 216:37-46. doi: 10.1016/ j.jconrel.2015.06.033

17. Stolk DA, de Haas A, Vree J, Duinkerken S, Lübbers J, van de Ven R, et al. Lipo-Based Vaccines as an Approach to Target Dendritic Cells for Induction of T- and iNKT Cell Responses. Front Immunol (2020) 11(990). doi: 10.3389/ fimmu.2020.00990

18. Nijen Twilhaar MK, Czentner L, van Nostrum CF, Storm G, den Haan JMM. Mimicking Pathogens to Augment the Potency of Liposomal Cancer Vaccines. Pharmaceutics (2021) 13(7). doi: 10.3390/pharmaceutics13070954

19. Heuts J, Jiskoot W, Ossendorp F, van der Maaden K. Cationic NanoparticleBased Cancer Vaccines. Pharmaceutics (2021) 13(5). doi: 10.3390/ pharmaceutics 13050596

20. Nagy NA, de Haas AM, Geijtenbeek TBH, van Ree R, Tas SW, van Kooyk Y, et al. Therapeutic Liposomal Vaccines for Dendritic Cell Activation or Tolerance. Front Immunol (2021) 12:674048-8. doi: 10.3389/fimmu.2021. 674048

21. den Haan JM, Lehar SM, Bevan MJ. CD8(+) But Not CD8(-) Dendritic Cells Cross-Prime Cytotoxic T Cells In Vivo. J Exp Med (2000) 192(12):1685-96. doi: 10.1084/jem.192.12.1685

22. Dudziak D, Kamphorst AO, Heidkamp GF, Buchholz VR, Trumpfheller C, Yamazaki S, et al. Differential Antigen Processing by Dendritic Cell Subsets In Vivo. Science (2007) 315(5808):107-11. doi: 10.1126/science.1136080

23. Sancho D, Joffre OP, Keller AM, Rogers NC, Martínez D, Hernanz-Falcón P, et al. Identification of a Dendritic Cell Receptor That Couples Sensing of Necrosis to Immunity. Nature (2009) 458(7240):899-903. doi: 10.1038/ nature 07750

24. Guilliams M, Ginhoux F, Jakubzick C, Naik SH, Onai N, Schraml BU, et al. Dendritic Cells, Monocytes and Macrophages: A Unified Nomenclature Based on Ontogeny. Nat Rev Immunol (2014) 14(8):571-8. doi: 10.1038/ nri3712

25. Hildner K, Edelson BT, Purtha WE, Diamond M, Matsushita H, Kohyama M, et al. Batf3 Deficiency Reveals a Critical Role for CD8 $\alpha^{+}$Dendritic Cells in 
Cytotoxic T Cell Immunity. Science (2008) 322(5904):1097-100. doi: 10.1126/ science. 1164206

26. Böttcher JP, Reis e Sousa C. The Role of Type 1 Conventional Dendritic Cells in Cancer Immunity. Trends Cancer (2018) 4(11):784-92. doi: 10.1016/ j.trecan.2018.09.001

27. Wculek SK, Cueto FJ, Mujal AM, Melero I, Krummel MF, Sancho D. Dendritic Cells in Cancer Immunology and Immunotherapy. Nat Rev Immunol (2020) 20(1):7-24. doi: 10.1038/s41577-019-0210-Z

28. Ahrens S, Zelenay S, Sancho D, Hanč P, Kjær S, Feest C, et al. F-Actin Is an Evolutionarily Conserved Damage-Associated Molecular Pattern Recognized by DNGR-1, a Receptor for Dead Cells. Immunity (2012) 36(4):635-45. doi: 10.1016/j.immuni.2012.03.008

29. Zelenay S, Keller AM, Whitney PG, Schraml BU, Deddouche S, Rogers NC, et al. The Dendritic Cell Receptor DNGR-1 Controls Endocytic Handling of Necrotic Cell Antigens to Favor Cross-Priming of CTLs in Virus-Infected Mice. J Clin Invest (2012) 122(5):1615-27. doi: 10.1172/JCI60644

30. Murphy TL, Murphy KM. Dendritic Cells in Cancer Immunology. Cell Mol Immunol (2021) 19:3-13. doi: 10.1038/s41423-021-00741-5

31. Ferris ST, Durai V, Wu R, Theisen DJ, Ward JP, Bern MD, et al. Cdc1 Prime and Are Licensed by CD4+ T Cells to Induce Anti-Tumour Immunity. Nature (2020) 584(7822):624-9. doi: 10.1038/s41586-020-2611-3

32. Masterman KA, Haigh OL, Tullett KM, Leal-Rojas IM, Walpole C, Pearson FE, et al. Human CLEC9A Antibodies Deliver NY-ESO-1 Antigen to CD141 (+) Dendritic Cells to Activate Naïve and Memory NY-ESO-1-Specific CD8 (+) T Cells. J Immunother Cancer (2020) 8(2). doi: 10.1136/jitc-2020-000691

33. Pearson FE, Tullett KM, Leal-Rojas IM, Haigh OL, Masterman KA, Walpole C, et al. Human CLEC9A Antibodies Deliver Wilms' Tumor 1 (WT1) Antigen to CD141(+) Dendritic Cells to Activate Naïve and Memory WT1-Specific CD8(+) T Cells. Clin Transl Immunol (2020) 9(6):e1141. doi: 10.1002/ cti2.1141

34. Sancho D, Mourão-Sá D, Joffre OP, Schulz O, Rogers NC, Pennington DJ, et al. Tumor Therapy in Mice via Antigen Targeting to a Novel, DC-Restricted C-Type Lectin. J Clin Invest (2008) 118(6):2098-110. doi: 10.1172/JCI34584

35. Mebius RE, Kraal G. Structure and Function of the Spleen. Nat Rev Immunol (2005) 5(8):606-16. doi: 10.1038/nril669

36. Crocker PR, Paulson JC, Varki A. Siglecs and Their Roles in the Immune System. Nat Rev Immunol (2007) 7(4):255-66. doi: 10.1038/nri2056

37. Macauley MS, Crocker PR, Paulson JC. Siglec-Mediated Regulation of Immune Cell Function in Disease. Nat Rev Immunol (2014) 14:653. doi: $10.1038 /$ nri3737

38. Grabowska J, Lopez-Venegas MA, Affandi AJ, den Haan JMM. CD169+ Macrophages Capture and Dendritic Cells Instruct: The Interplay of the Gatekeeper and the General of the Immune System. Front Immunol (2018) 9 (2472). doi: 10.3389/fimmu.2018.02472

39. Puryear WB, Akiyama H, Geer SD, Ramirez NP, Yu X, Reinhard BM, et al. Interferon-Inducible Mechanism of Dendritic Cell-Mediated HIV-1 Dissemination Is Dependent on Siglec-1/Cd169. PloS Pathog (2013) 9(4): e1003291. doi: 10.1371/journal.ppat.1003291

40. Puryear WB, Yu X, Ramirez NP, Reinhard BM, Gummuluru S. HIV-1 Incorporation of Host-Cell-Derived Glycosphingolipid GM3 Allows for Capture by Mature Dendritic Cells. Proc Natl Acad Sci USA (2012) 109 (19):7475-80. doi: 10.1073/pnas.1201104109

41. Lempp FA, Soriaga LB, Montiel-Ruiz M, Benigni F, Noack J, Park Y-J, et al. Lectins Enhance SARS-CoV-2 Infection and Influence Neutralizing Antibodies. Nature (2021) 598(7880):342-7. doi: 10.1038/s41586-02103925-1

42. Izquierdo-Useros N, Lorizate M, Puertas MC, Rodriguez-Plata MT, Zangger N, Erikson E, et al. Siglec-1 Is a Novel Dendritic Cell Receptor That Mediates HIV-1 Trans-Infection Through Recognition of Viral Membrane Gangliosides. PloS Biol (2012) 10(12):e1001448. doi: 10.1371/journal.pbio. 1001448

43. van Dinther D, Veninga H, Iborra S, Borg EGF, Hoogterp L, Olesek K, et al. Functional CD169 on Macrophages Mediates Interaction With Dendritic Cells for CD8+ T Cell Cross-Priming. Cell Rep (2018) 22(6):1484-95. doi: 10.1016/j.celrep.2018.01.021

44. Backer R, Schwandt T, Greuter M, Oosting M, Jüngerkes F, Tüting T, et al. Effective Collaboration Between Marginal Metallophilic Macrophages and
CD8+ Dendritic Cells in the Generation of Cytotoxic T Cells. Proc Natl Acad Sci (2010) 107(1):216-21. doi: 10.1073/pnas.0909541107

45. Xu F, Bandara A, Akiyama H, Eshaghi B, Stelter D, Keyes T, et al. MembraneWrapped Nanoparticles Probe Divergent Roles of GM3 and Phosphatidylserine in Lipid-Mediated Viral Entry Pathways. Proc Natl Acad Sci USA (2018) 115(39):E9041-e9050. doi: 10.1073/pnas.1804292115

46. Yu X, Feizpour A, Ramirez N-GP, Wu L, Akiyama H, Xu F, et al. Glycosphingolipid-Functionalized Nanoparticles Recapitulate CD169Dependent HIV-1 Uptake and Trafficking in Dendritic Cells. Nat Commun (2014) 5:4136-6. doi: 10.1038/ncomms5136

47. Yu X, Xu F, Ramirez N-GP, Kijewski SDG, Akiyama H, Gummuluru S, et al. Dressing Up Nanoparticles: A Membrane Wrap to Induce Formation of the Virological Synapse. ACS Nano (2015) 9(4):4182-92. doi: 10.1021/ acsnano.5b00415

48. Grabowska J, Affandi AJ, van Dinther D, Nijen Twilhaar MK, Olesek K, Hoogterp L, et al. Liposome Induction of CD8(+) T Cell Responses Depends on CD169(+) Macrophages and Batf3-Dependent Dendritic Cells and Is Enhanced by GM3 Inclusion. J Contr Rel (2021) 331:309-20. doi: 10.1016/ j.jconrel.2021.01.029

49. Nijen Twilhaar MK, Czentner L, Grabowska J, Affandi AJ, Lau CYJ, Olesek K, et al. Optimization of Liposomes for Antigen Targeting to Splenic CD169(+) Macrophages. Pharmaceutics (2020) 12(12). doi: 10.3390/ pharmaceutics 12121138

50. Edgar LJ, Kawasaki N, Nycholat CM, Paulson JC. Targeted Delivery of Antigen to Activated CD169+ Macrophages Induces Bias for Expansion of CD8+ T Cells. Cell Chem Biol (2019) 26(1):131-6.e4. doi: 10.1016/ j.chembiol.2018.10.006

51. Kawasaki N, Vela JL, Nycholat CM, Rademacher C, Khurana A, van Rooijen N, et al. Targeted Delivery of Lipid Antigen to Macrophages via the CD169/ sialoadhesin Endocytic Pathway Induces Robust Invariant Natural Killer T Cell Activation. Proc Natl Acad Sci (2013) 110(19):7826-31. doi: 10.1073/ pnas. 1219888110

52. Zhivaki D, Borriello F, Chow OA, Doran B, Fleming I, Theisen DJ, et al. Inflammasomes Within Hyperactive Murine Dendritic Cells Stimulate LongLived T Cell-Mediated Anti-Tumor Immunity. Cell Rep (2020) 33(7):108381. doi: 10.1016/j.celrep.2020.108381

53. Feige E, Mendel I, George J, Yacov N, Harats D. Modified Phospholipids as Anti-Inflammatory Compounds. Curr Opin Lipidol (2010) 21(6):525-9. doi: 10.1097/MOL.0b013e32833f2fcb

54. Zhivaki D, Kagan JC. Innate Immune Detection of Lipid Oxidation as a Threat Assessment Strategy. Nat Rev Immunol (2021), 1-9. doi: 10.1038/ s41577-021-00618-8

55. Paßlick D, Piradashvili K, Bamberger D, Li M, Jiang S, Strand D, et al. Delivering All in One: Antigen-Nanocapsule Loaded With Dual Adjuvant Yields Superadditive Effects by DC-Directed T Cell Stimulation. J Contr Rel (2018) 289:23-34. doi: 10.1016/j.jconrel.2018.09.008

56. Hatscher L, Lehmann CHK, Purbojo A, Onderka C, Liang C, Hartmann A, et al. Select Hyperactivating NLRP3 Ligands Enhance the T(H)1- and T(H)17Inducing Potential of Human Type 2 Conventional Dendritic Cells. Sci Signal (2021) 14(680). doi: 10.1126/scisignal.abe1757

57. Klaas M, Oetke C, Lewis LE, Erwig LP, Heikema AP, Easton A, et al. Sialoadhesin Promotes Rapid Proinflammatory and Type I IFN Responses to a Sialylated Pathogen, Campylobacter Jejuni. J Immunol (2012) 189 (5):2414-22. doi: 10.4049/jimmunol.1200776

58. Affandi AJ, Olesek K, Grabowska J, Nijen Twilhaar MK, Rodríguez E, Saris A, et al. CD169 Defines Activated CD14(+) Monocytes With Enhanced CD8(+) T Cell Activation Capacity. Front Immunol (2021) 12:697840. doi: 10.3389/ fimmu.2021.697840

59. Affandi AJ, Grabowska J, Olesek K, Lopez Venegas M, Barbaria A, Rodríguez E, et al. Selective Tumor Antigen Vaccine Delivery to Human CD169(+) Antigen-Presenting Cells Using Ganglioside-Liposomes. Proc Natl Acad Sci USA (2020) 117(44):27528-39. doi: 10.1073/pnas.2006186117

60. Grabowska J, Stolk DA, Nijen Twilhaar MK, Ambrosini M, Storm G, van der Vliet HJ, et al. Liposomal Nanovaccine Containing $\alpha$-Galactosylceramide and Ganglioside GM3 Stimulates Robust CD8(+) T Cell Responses via CD169(+) Macrophages and Cdc1. Vaccines (Basel) (2021) 9(1). doi: 10.3390/ vaccines 9010056 
61. Patinote C, Karroum NB, Moarbess G, Cirnat N, Kassab I, Bonnet P-A, et al. Agonist and Antagonist Ligands of Toll-Like Receptors 7 and 8: Ingenious Tools for Therapeutic Purposes. Eur J Med Chem (2020) 193:112238-8. doi: 10.1016/j.ejmech.2020.112238

62. Effenberg R, Turánek Knötigová P, Zyka D, Čelechovská H, Mašek J, Bartheldyová E, et al. Nonpyrogenic Molecular Adjuvants Based on Norabu-Muramyldipeptide and Norabu-Glucosaminyl Muramyldipeptide: Synthesis, Molecular Mechanisms of Action, and Biological Activities In Vitro and In Vivo. J Med Chem (2017) 60(18):7745-63. doi: 10.1021/ acs.jmedchem.7b00593

63. Blüml S, Kirchberger S, Bochkov VN, Krönke G, Stuhlmeier K, Majdic O, et al. Oxidized Phospholipids Negatively Regulate Dendritic Cell Maturation Induced by TLRs and CD40. J Immunol (2005) 175(1):501-8. doi: 10.4049/ jimmunol.175.1.501

64. Chu LH, Indramohan M, Ratsimandresy RA, Gangopadhyay A, Morris EP, Monack DM, et al. The Oxidized Phospholipid oxPAPC Protects From Septic Shock by Targeting the Non-Canonical Inflammasome in Macrophages. Nat Commun (2018) 9(1):996. doi: 10.1038/s41467-01803409-3

65. Erlich Z, Shlomovitz I, Edry-Botzer L, Cohen H, Frank D, Wang H, et al. Macrophages, Rather Than DCs, Are Responsible for Inflammasome Activity in the GM-CSF BMDC Model. Nat Immunol (2019) 20(4):397-406. doi: 10.1038/s41590-019-0313-5

66. Zanoni I, Tan Y, Di Gioia M, Springstead JR, Kagan JC. By Capturing Inflammatory Lipids Released From Dying Cells, the Receptor CD14 Induces Inflammasome-Dependent Phagocyte Hyperactivation. Immunity (2017) 47(4):697-709.e3. doi: 10.1016/j.immuni.2017.09.010

67. McDaniel MM, Kottyan LC, Singh H, Pasare C. Suppression of Inflammasome Activation by IRF8 and IRF4 in cDCs Is Critical for T Cell Priming. Cell Rep (2020) 31(5):107604-4. doi: 10.1016/ j.celrep.2020.107604

68. Singh J, Ranganathan R. Mixing of Oxidized and Bilayer Phospholipids. Biochim Biophys Acta (BBA) Biomembr (2015) 1848(7):1472-80. doi: 10.1016/ j.bbamem.2015.03.027
69. Gay B, Cardot JM, Schnell C, van Hoogevest P, Gygax D. Comparative Pharmacokinetics of Free Muramyl Tripeptide Phosphatidyl Ethanolamine (MTP-PE) and Liposomal MTP-PE. J Pharm Sci (1993) 82(10):997-1001. doi: 10.1002/jps.2600821005

70. Utsugi T, Nii A, Fan D, Pak CC, Denkins Y, van Hoogevest P, et al. Comparative Efficacy of Liposomes Containing Synthetic Bacterial Cell Wall Analogues for Tumoricidal Activation of Monocytes and Macrophages. Cancer Immunol Immunother (1991) 33(5):285-92. doi: 10.1007/BF01756592

71. Martin MD, Badovinac VP. Defining Memory CD8 T Cell. Front Immunol (2018) 9(2692). doi: 10.3389/fimmu.2018.02692

72. Kretschmer L, Flossdorf M, Mir J, Cho Y-L, Plambeck M, Treise I, et al. Differential Expansion of T Central Memory Precursor and Effector Subsets Is Regulated by Division Speed. Nat Commun (2020) 11(1):113. doi: 10.1038/ s41467-019-13788-w

Conflict of Interest: The authors declare that the research was conducted in the absence of any commercial or financial relationships that could be construed as a potential conflict of interest.

Publisher's Note: All claims expressed in this article are solely those of the authors and do not necessarily represent those of their affiliated organizations, or those of the publisher, the editors and the reviewers. Any product that may be evaluated in this article, or claim that may be made by its manufacturer, is not guaranteed or endorsed by the publisher.

Copyright (c) 2022 Nijen Twilhaar, Czentner, Bouma, Olesek, Grabowska, Wang, Affandi, Belt, Kalay, van Nostrum, van Kooyk, Storm and den Haan. This is an openaccess article distributed under the terms of the Creative Commons Attribution License (CC BY). The use, distribution or reproduction in other forums is permitted, provided the original author(s) and the copyright owner(s) are credited and that the original publication in this journal is cited, in accordance with accepted academic practice. No use, distribution or reproduction is permitted which does not comply with these terms. 